\title{
A COMPLETE DC ANALYSIS OF THE SERIES RESONANT CONVERTER
}

\author{
V. VORPÉRIAN AND SLOBODAN ĆUK
}

California Instifute of Technology

Pasadena, California

\section{ABSTRACT}

The $d c-t o-d c$ conversion ratio of the series resonant converter has been determined in the general discontinuous and continuous conduction modes. This new analysis gives a complete description of the dc operation of the circuit for any load and for any switching frequency.

\section{INTRODUCTION}

The series resonant converter shown in Fig. 1 is one class of dc-to-dc converters that, while quite widely used is not as well understood as the class of pulse-width-modulated converters (buck, boost, Cuk, etc.). The state-space averaging technique $[1,2,3]$, that has proved to be so fruitful in the analysis of pulse-width-modulated converters, is not applicable to resonant converters because the principal time constants are not long compared to the switching period. Nevertheless, the same kind of analytical results are as desirable for resonant converters as for pwm converters, in particular the dc-to-dc conversion ratio.

Previous analyses $[4,5$, and 6] have considered the operation of this circuit as a function of some, for this purpose, inconvenient parameter such as the diode (D1) conduction angle, and have not determined the conversion ratio $M$ explicity.

In this paper a thorough analysis of the conversion ratio $M=V / V_{g}$ as a function of the switching frequency $f_{S}$ and the load $R$ is given for the series resonant converter in the general continuous and discontinuous conduction modes. Experimental results obtained for a resonant converter with resonant frequency $\mathrm{f}_{0}=35.7 \mathrm{kHz}$ and $\mathrm{f}_{0}=157 \mathrm{kHz}$ are in good agreement with predicted values.

This work was sponsored by the Office of Naval Research, Washington DC, under Contract N00014-78C-0757, and by the Naval Ocean Systems Center, San Diego, CA.
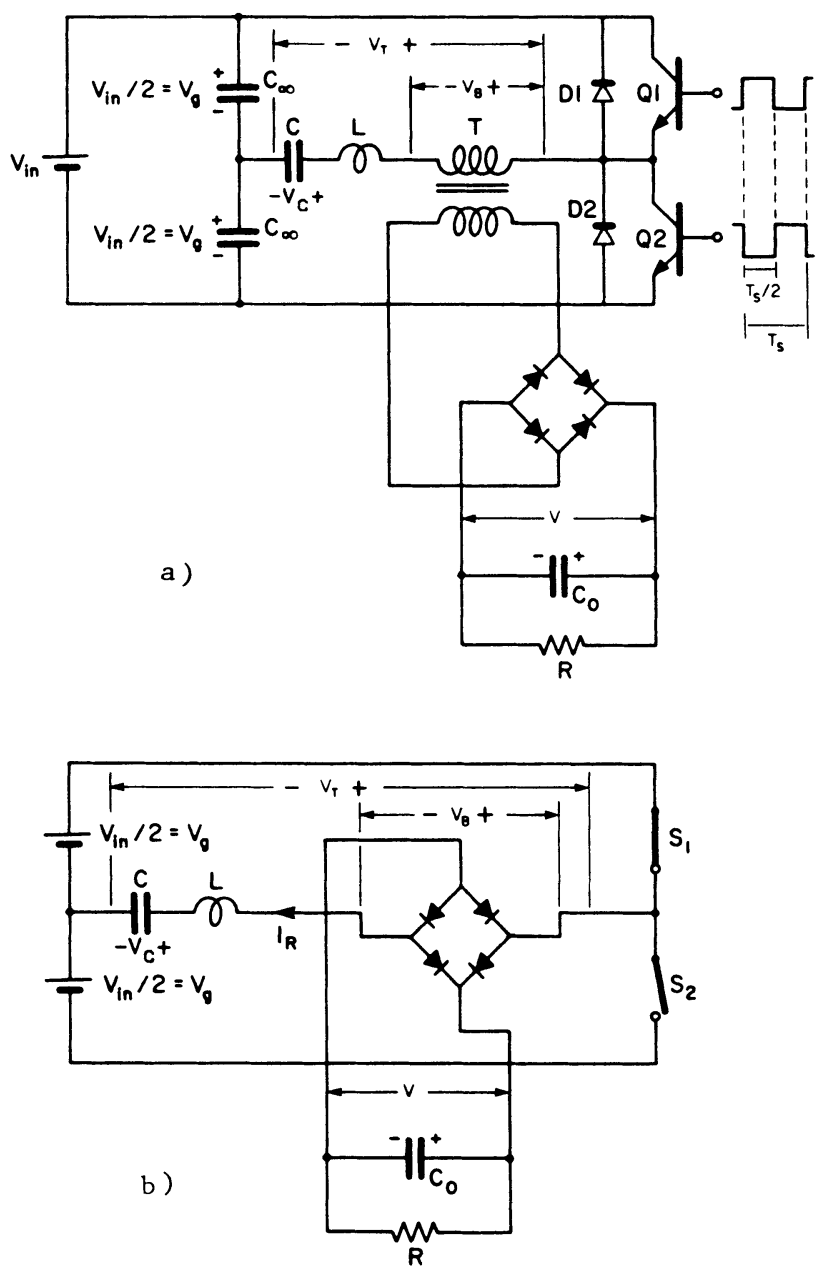

Fig. 1. (a) The series resonant converter and (b) its ideal equivalent circuit.

\section{THEORY OF OPERATION}

The circuit in Fig. $1 \mathrm{~b}$ is equivalent to the circuit in Fig. la if we assume that the components are ideal and that $C_{\infty} \gg C$. The various voltages $\mathrm{v}_{\mathrm{T}}, \mathrm{v}_{\mathrm{B}}, \mathrm{v}_{\mathrm{C}}, \mathrm{V}$ and the current $\mathrm{I}_{\mathrm{R}}$ are defined according to Fig. 1b. The bidirectional switches 
S1 and S2 operate at $50 \%$ duty ratio for a duration $\mathrm{T}_{\mathrm{S}} / 2$, where $\mathrm{T}_{\mathrm{S}}$ is defined as the switching interval. The switching frequency $f_{s}$ is given by

$$
\mathrm{f}_{\mathrm{s}}=\frac{1}{\mathrm{~T}_{\mathrm{s}}} \triangleq \text { switching frequency }
$$

When Q1 is turned $\mathrm{ON}$ and simultaneously Q2 turned OFF, the diode D2 will become reverse biased by $V_{\text {in }}=2 V_{g}$, and consequently $\mathrm{s} 2$ will be opened. The pattern repeats when $\mathrm{Q} 2$ is turned $\mathrm{ON}$ and $\mathrm{Q1}$ is turned OFF. At no time Q1 and Q2 are switched OFF simultaneously. Later in Section 7 we will remove this restriction and discuss the special case when $\mathrm{Q} 1$ and $\mathrm{Q} 2$ are switched OFF simultaneously.

The most general current and voltage waveforms during $\mathrm{T}_{\mathbf{S}} / 2$ ( $\mathrm{S} 1$ ON and $\mathrm{S} 2$ OFF) are shown in Figs. 2-3. The waveforms during the following cycle (S2 ON and S1 OFF), parts of which are shown, are the same as the waveforms in the preceding cycle but of opposite sign because of the symmetry of the circuit.

The voltage $V_{B}$ at the input side of the bridge is controlled by the sign of the resonant current $I_{R}$ and its peak value is equal to the output voltage $V$. The resonant current $I_{R}$ consists of piecewise currents each of frequency equal to the resonant frequency given by

$$
\mathrm{f}_{0}=\frac{1}{2 \pi \sqrt{\mathrm{LC}}}=\frac{1}{\mathrm{~T}_{0}} \triangleq \text { resonant frequency }
$$

From the current waveforms in Figs. 2 and 3 we see that there are two different types of discontinuous and continuous conduction modes. In the discontinuous conduction mode the resonant current $I_{R}$ terminates after completing $n$ full half cycles denoted by $i_{1}(t)$ through $i_{n}(t)$ as shown in Figs. 2a,b. This is followed by a period of no conduction even though, we point out that, the switch $S 1$ is closed and capable of conduction. The reason for the discontinuity in the current $I_{R}$, as will be shown later, is that the bridge becomes reverse biased. The two different discontinuous conduction modes correspond to whether $n$ is odd or even and are appropriately called odd or even type $n \mathrm{dcm}$. We can see that in general for type $n$ $\mathrm{dcm}$ to occur we must have

$$
\frac{\mathrm{T}_{\mathrm{s}}}{2}>\frac{\mathrm{nT}_{0}}{2} \text { or } 0<\frac{\mathrm{f}_{\mathrm{s}}}{\mathrm{f}_{0}}<\frac{1}{\mathrm{n}}
$$

The frequency interval given by (3) is the largest possible interval for type $\mathrm{n} \mathrm{dcm}$ to occur. For a given load $\mathrm{R}$, however, the interval in which type $n$ dcm occurs is more restricted than (3) and can be written as

$$
0<C_{2}(R, n)<\frac{f_{s}}{f_{0}}<C_{1}(R, n) \leq \frac{1}{n},
$$

where $C_{1}(R, n)$ and $C_{2}(R, n)$ are constants depending on the load $\mathrm{R}$ which will be determined in the next section.
We now define the load parameter $Q$ as follows

$$
Q=\frac{\omega_{0} L}{R}
$$

This $Q$ of course is not to be confused with the $Q_{\text {coil }}$ of the inductor $L$ which we have assumed to be ideal $\left(Q_{\text {coil }} \rightarrow \infty\right)$.

In the continuous conduction mode the current $I_{R}$ never ceases to flow as shown in Figs. $3 a, b$. For any switching frequency less than the resonant frequency, $\mathrm{f}_{\mathrm{S}}<\mathrm{f}_{\mathrm{O}}$, the $\mathrm{Q}$ determines whether the circuit is operating in discontinuous or continuous conduction mode: when $Q$ is increased above a critical value dependent on $f_{S}$, the circuit will enter continuous conduction mode $(\mathrm{ccm})$. In this section we will only describe the operation of the continuous conduction mode and in a later section determine the critical values of $Q$. There are two different types of continuous conduction mode depending on whether D1 (D2) or Q1 (Q2) conducts first when $S 1$ (S2) is closed. Fig. 3a shows Q1 conducting first at the instant $\mathrm{S} 1$ is closed. This is followed by $\mathrm{D} 1$ and $\mathrm{Q} 1$ conducting alternately for $n$ full half cycles after which, while D1 is conducting Q2 is switched ON and S1 is turned OFF. Steady state periodicity of $I_{R}$ requires that if $\mathrm{Q} 1$ conducts first, $\mathrm{Dl}$ should conduct last. This implies that $n$ can only be even or zero. This type of continuous conduction mode is called ttype $n \mathrm{ccm}$, where $n$ refers to the number of full half cycles of $I_{R}$ while $S 1$ or $S 2$ is $O N$, and the positive sign refers to the fact that $I_{R}$ and $V_{T}$ have the same sign when $S 1$ or $S 2$ is turned ON (or immediately afterwards). Referring to Fig. 3a or Fig. 6a, we note that for this case the time interval $\mathrm{T}_{\mathrm{S}} / 2-\mathrm{nT}_{0} / 2$ must satisfy the following inequality;

$$
\frac{\mathrm{T}_{0}}{2}<\frac{\mathrm{T}_{\mathrm{s}}}{2}-\frac{\mathrm{nT}_{0}}{2}<2 \cdot \frac{\mathrm{T}_{0}}{2} \text { or } \frac{1}{\mathrm{n}+2}<\frac{\mathrm{f}_{\mathrm{s}}}{\mathrm{f}_{0}}<\frac{1}{\mathrm{n}+1}
$$

Eq. (6) gives the frequency interval in which ttype n ccm can occur.

Fig. 3b shows $D 1$ conducting first at the instant $\mathrm{S} 1$ is closed. This is followed by $\mathrm{Q} 1$ and D1 conducting alternately for $n$ full half cycles after which Q1 while conducting is switched OFF and Q2 is switched ON (but D2 will conduct first). As before, periodicity requires $n$ to be even or zero. This type of continuous conduction mode is called -type $n \mathrm{ccm}$ where the negative sign refers to the fact that $I_{R}$ and $V_{T}$ have opposite signs when $S 1$ or $\mathrm{S} 2$ is turned ON (or immediately afterwards). Referring to Fig. $3 \mathrm{~b}$ or Fig. $6 \mathrm{~b}$ we see that for this case the time interval $\mathrm{T}_{\mathrm{S}} / 2-\mathrm{nT}_{0} / 2$ must satisfy the following inequality,

$$
0<\frac{\mathrm{T}_{\mathrm{s}}}{2}-\frac{\mathrm{nT}_{0}}{2}<\frac{\mathrm{T}_{0}}{2} \text { or } \frac{1}{\mathrm{n}+1}<\frac{\mathrm{f}_{\mathrm{s}}}{\mathrm{f}_{0}}<\frac{1}{\mathrm{n}}
$$

Eq. (7) gives the frequency interval in which 


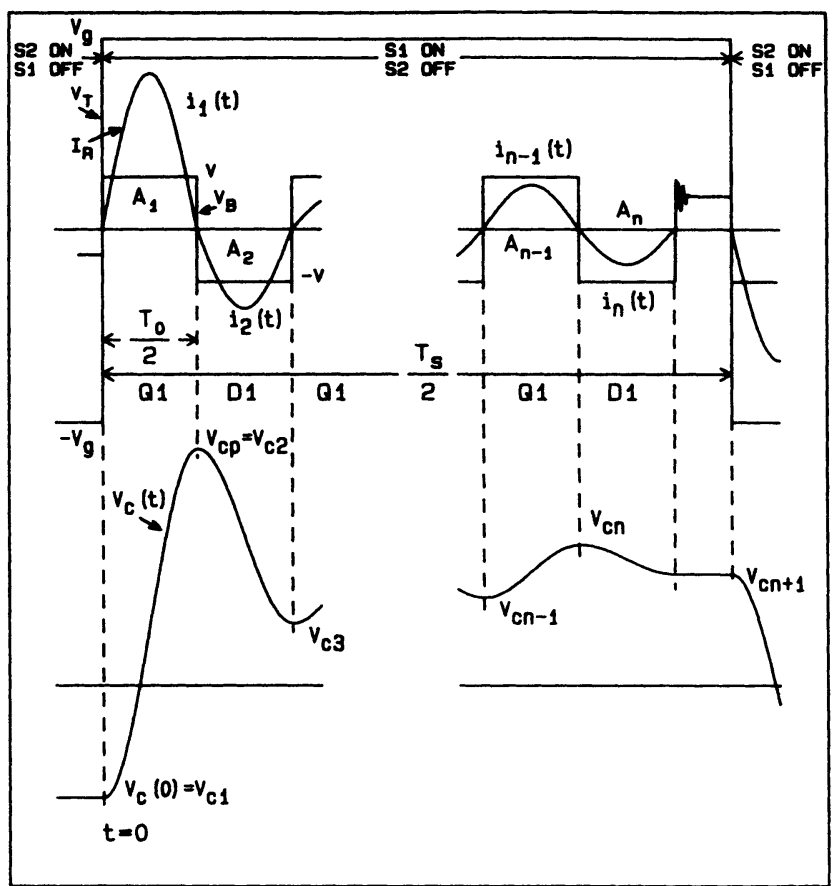

a)

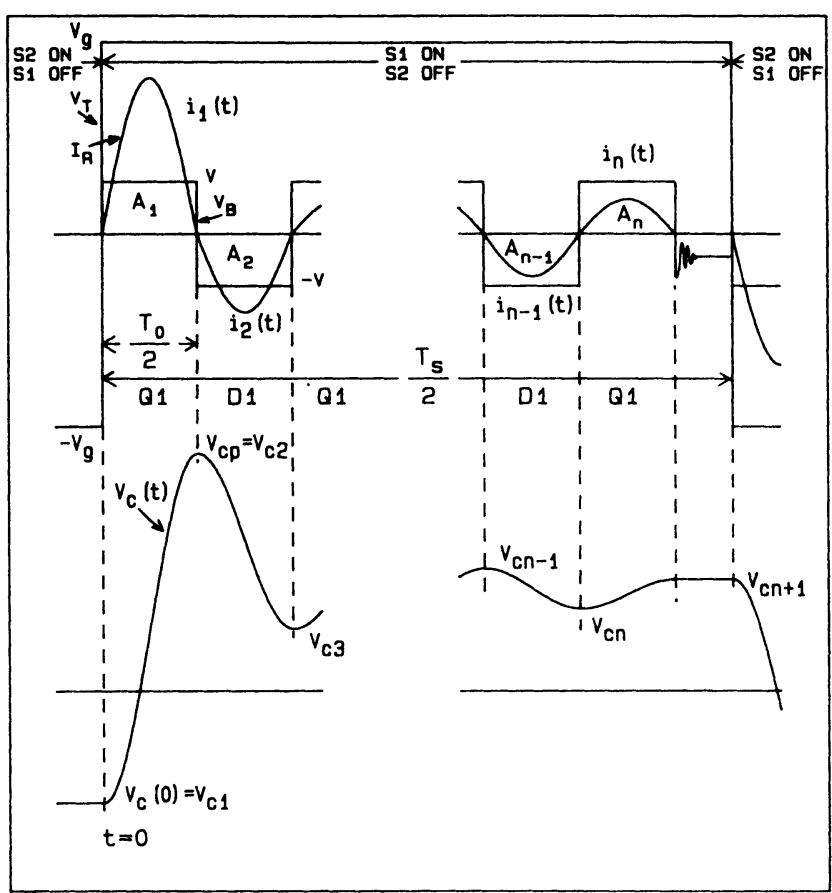

b)

Fig. 2. Voltage and current waveforms in the discontinuous conduction mode (a) even type $n \mathrm{dcm}$ and (b) odd type $n \mathrm{dcm}$.

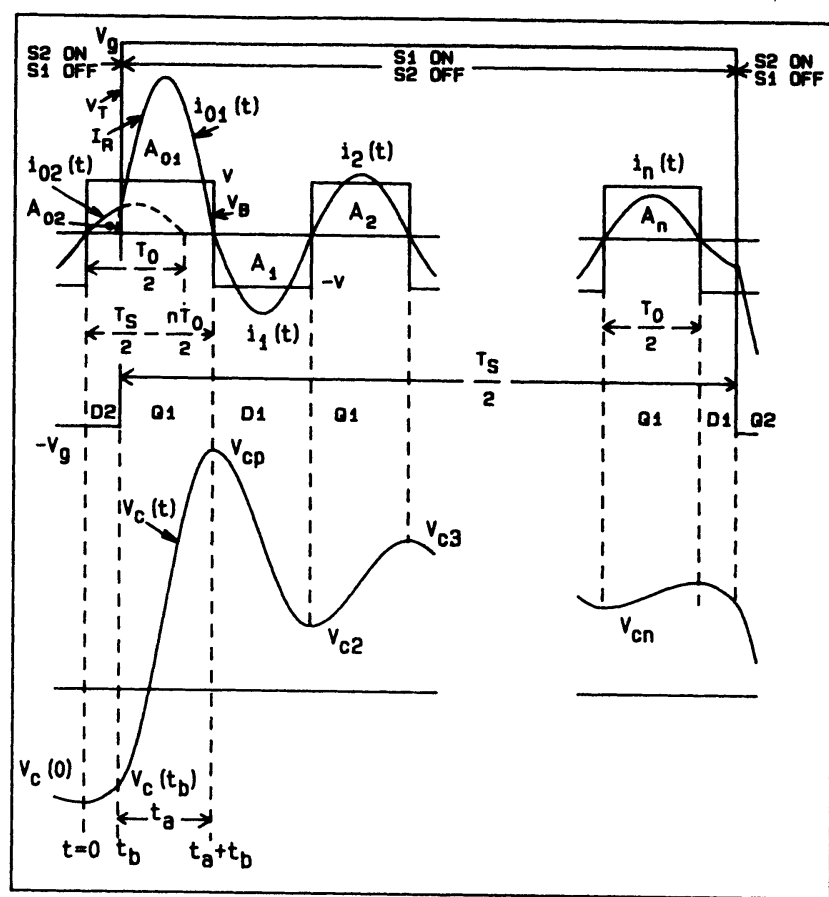

a)

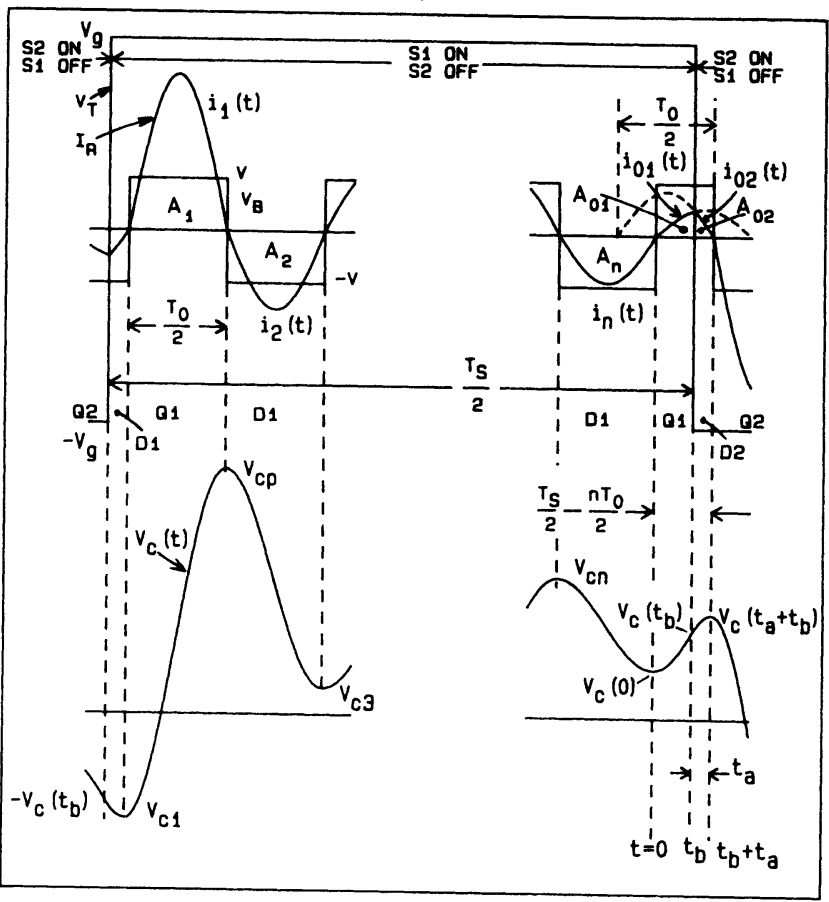

b)

Fig. 3. Voltage and current waveforms in the continuous conduction mode $(a)+t y p e n$ $\mathrm{ccm}(b)$-type $n \mathrm{ccm}$. 
-type $\mathrm{n} \mathrm{ccm}$ can occur. The frequency intervals given by Eqs. (6) and (7) can be more restricted depending on the load $R$. This is shown in Table 1 where $B_{1}(Q, n)$ and $B_{2}(Q, n)$ are constants depending on $\mathrm{n}$ and $\mathrm{Q}$ and will be determined in Section 6 .

Before going on to the analysis, we would like to show the consistency of the nomenclature of the two types of continuous and discontinuous conduction modes. We have

$$
\begin{aligned}
& \text { Even t type } \mathrm{n} \mathrm{dcm} \\
& \text { Odd +type } \mathrm{n} \mathrm{dcm} \\
& \text { Even t type } \mathrm{n} \mathrm{ccm} \\
& \text { Even -type } \mathrm{n} \mathrm{ccm}
\end{aligned}
$$

Since the positive sign with $\mathrm{dcm}$ and the word even with ccm are redundant, we omit them and obtain the nomenclature given above in (b).

The results are summarized in Table 1 .

\section{ANALYSIS OF THE CONVERSION RATIO IN THE DISCONTINUOUS CONDUCTION MODE}

This mode of operation, as mentioned earlier, occurs when the circuit is excited below resonance, and the reason for its occurence is that the output rectifier bridge becomes reverse biased. In this section we will show that the conversion ratio $M$, for the even discontinuous conduction mode, is a linear function of the switching frequency and the load. For the odd discontinuous conduction mode, it will be shown that $M$ is insensitive to variations in load and switching frequency.

We define now two additional parameters:

$$
\begin{aligned}
& \gamma=\frac{\mathrm{f}_{0}}{\mathrm{f}_{\mathrm{s}}} \pi \text { or } \frac{\mathrm{f}_{\mathrm{s}}}{\mathrm{f}_{0}}=\frac{\pi}{\gamma} \\
& \mathrm{K}=\frac{\mathrm{Q} \cdot \gamma}{2}=\frac{\pi}{2 \mathrm{RC} \omega_{\mathrm{S}}}
\end{aligned}
$$

The conversion ratio is defined as

$$
M=\frac{\mathrm{V}}{\mathrm{V}_{\mathrm{g}}} \text {, }
$$

where $V_{g}=V_{i n} / 2$ as shown in Fig. $1 b$. We proceed now with the analysis of $M$ in both types of discontinuous conduction mode.

\section{Even type $n \mathrm{dcm}$ ( $n=$ even)}

The output current $I_{0}$ is the average rectified resonant current $\left|I_{R}(t)\right|$ :

$$
I_{0}=\frac{V}{R}=\frac{2}{T_{s}} \int_{0}^{T / 2}\left|I_{R}(t)\right| d t
$$

Referring to Fig. 2a this integral can be expressed in terms of the areas, $A_{n}$, under each full half cycle of $I_{R}$. We can then write (11) as

$$
\frac{\mathrm{V}}{\mathrm{R}}=\frac{2}{\mathrm{~T}_{\mathrm{s}}} \sum_{\mathrm{m}=1}^{\mathrm{n}} \mathrm{A}_{\mathrm{m}} .
$$

Using definition (9) we can write (12) as

$$
\sum_{m=1}^{n} A_{m}=2 c v k \text {. }
$$

Next we consider the power delivered to the circuit, $P_{i n}$, and the power delivered to the load, $P_{0}$, which in the ideal case are equal:

$$
P_{\text {in }}=\frac{2}{T_{s}} \int_{0}^{T / 2} V_{g} I_{R}(t) d t=\frac{2}{T_{s}} v_{g} \sum_{m=1}^{n} A_{m}(-1)^{m+1}
$$

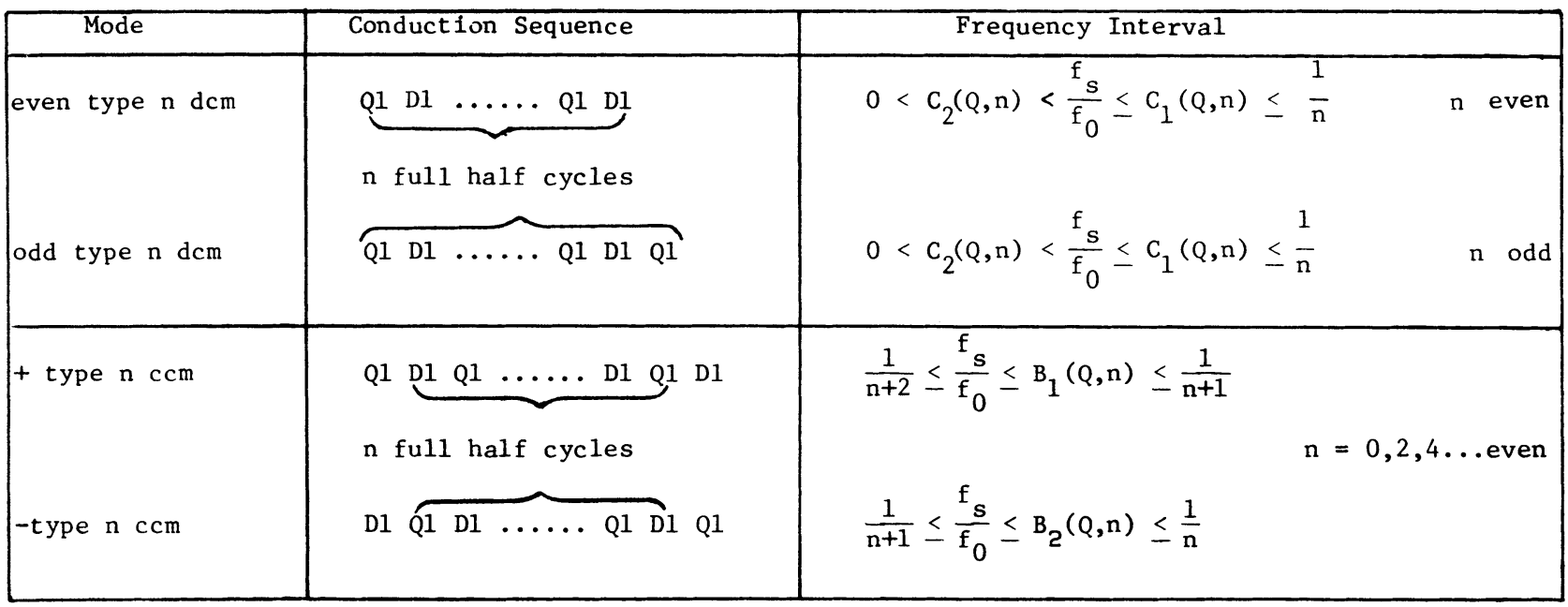

Table 1 


$$
P_{0}=\frac{2}{T_{s}} \int_{0}^{T_{s} / 2} V\left|I_{R}(t)\right| d t=\frac{2}{T_{s}} v \sum_{m=1}^{n} A_{m}
$$

Equating (14) and (15) we obtain for $M=V / V_{g}$

$$
M=\frac{\sum_{m=1}^{n} A_{m}(-1)^{m+1}}{2 C V K}
$$

The equations for the currents $i_{1}(t)$ through $i_{n}(t)$ can be determined by straightforward circuit analysis:

$$
i_{m}(t)=\omega_{0} c\left[v_{g}+(-1)^{m_{v}}-v_{c m}\right] \sin \omega_{0}\left(t-(m-1) \frac{T_{0}}{2}\right)
$$

$$
A_{m}=\int_{(m-1) T_{0} / 2}^{\mathrm{mT}_{0} / 2}\left|i_{m}(t)\right| d t=2 c\left[v_{g}-v_{c m}+(-1)^{m} v\right](-1)^{m+1}
$$

where,

$$
\begin{aligned}
\mathrm{v}_{\mathrm{cm}} \triangleq & \text { the initial voltage across the capacitor } \\
& \mathrm{C} \text { at the beginning of the } \mathrm{m}^{\text {th }} \text { half } \\
& \text { cycle (Fig. } 2 \mathrm{a}) .
\end{aligned}
$$

In equation (18) the $\mathrm{V}_{\mathrm{cm}}$ are unknown, however, we need on $1 y$ determine $v_{c l}=V_{c}(0)$, and $a$ recursive expression for $A_{m}$ can be determined by successive calculation of $\mathrm{V}_{\mathrm{cm}}=\mathrm{V}_{\mathrm{cm}-1}+(-1)^{\mathrm{m}_{\mathrm{m}-1}} / \mathrm{C}$ starting with $m=2$. The peak-to-peak capacitor voltage $v_{c p-p}$ and $V_{c l}$ are given by

$$
\begin{aligned}
& \mathrm{Cv}_{\mathrm{cp}-\mathrm{p}}=2 \mathrm{CV}_{\mathrm{c} 2}=2 \mathrm{~A}_{1}-\sum_{\mathrm{m}=1}^{\mathrm{n}} \mathrm{A}_{\mathrm{m}}(-1)^{\mathrm{m}+1}, \quad \mathrm{n} \text { even } \\
& \mathrm{v}_{\mathrm{cl}}=\mathrm{v}_{\mathrm{c} 2}-\frac{\mathrm{A}_{1}}{\mathrm{C}}=-\frac{1}{2 \mathrm{C}} \sum_{\mathrm{m}=1}^{\mathrm{n}} \mathrm{A}_{\mathrm{m}}(-1)^{\mathrm{m}+1}=-\mathrm{MKV}
\end{aligned}
$$

Now the desired recursive relation for $A_{m}$ can be determined

$$
A_{m}=2 C v_{g}\left[1-(2 m-1) M+M^{2} K\right]
$$

Now the summation in (16) can be computed

$$
\begin{aligned}
& \sum_{m=1}^{n} A_{m}(-1)^{m+1}=2 v_{g} C M, \quad n \text { even } \\
& \text { Substituting (22) into (16) we get for } M:
\end{aligned}
$$

$$
M=\frac{n}{K}=\frac{2 n}{Q \pi} \cdot \frac{f_{s}}{f_{0}},
$$

which is a linear function of load and switching frequency. Using (21) in (19) we get for the peak capacitor voltage and $V_{c 1}$

$$
\begin{aligned}
& v_{c p}=v_{g}\left[2-\frac{2 n}{K}+\frac{n^{2}}{K}\right], \\
& v_{c 1}=-n V
\end{aligned}
$$

\section{Odd type $n$ dem $(n=$ odd $)$}

The only difference between this case and the even type $\mathrm{n} \mathrm{dcm}$ is that in the summation in Eq. (22) $\mathrm{n}$ is odd and so we get

$$
\sum_{m=1}^{n} A_{m}(-1)^{m+1}=2 V_{g}\left[1-n M+k^{2}\right], \quad n \text { odd }
$$

which when substituted into (16) gives

$$
M=\frac{1}{n} \quad n=\text { odd }
$$

This result states that if the circuit is operating in an odd discontinuous conduction mode, then the conversion ratio $M$ is insensitive to load or switching frequency.

The peak capacitor voltage in this case is

$$
v_{c p}=v_{g}\left[2-\frac{2}{n}+\frac{k}{n^{2}}\right]
$$

\section{DISCUSSION ON DISCONTINUOUS CONDUCTION MODE}

\subsection{Boundary Between Two Discontinuous Conduction Modes}

Assume that the converter is operating in even type $\mathrm{m} \mathrm{dcm}$. The conversion ratio $M$ according to (23) is given by

$$
M_{m}=\frac{2 m}{\pi Q} \frac{f_{s}}{\mathrm{f}_{0}}
$$

and is plotted in Fig. 4 for three different cases. These are straight lines through the origin with slope $\frac{2 \mathrm{~m}}{\pi}$. It is clear that cases II and III correspond $\pi Q$ to higher values of $Q$ than case $I$. 
For type $\mathrm{m} \mathrm{dcm}$ to occur we require that $\mathrm{f}_{\mathrm{S}} / \mathrm{f}_{0} \leq \frac{1}{\mathrm{~m}}$, so that $(29)$ is valid in a region to the $1 \mathrm{e} \overline{\mathrm{ft}} \mathrm{m}^{\mathrm{m}} \mathrm{f}_{\mathrm{s}} / \mathrm{f}_{0}=1 / \mathrm{m}$ on the $\mathrm{M}$ vs. $\mathrm{f}_{\mathrm{s}} / \mathrm{f}_{0}$ plot. In case $I$, as the switching frequency is increased, $M_{m}$ will increase linearly until the converter enters odd type $(m-1) \mathrm{dcm}$ at $\mathrm{f}_{\mathrm{c}} / \mathrm{f}_{0}$. If we continue to increase $f_{s} / f_{0}$, say up to $f_{d} / f_{0}$, the conversion ratio $M$ will stay at a constant value of $1 /(m-1)$ because of operation in odd type $(\mathrm{m}-1) \mathrm{dcm}$. (To complete the discussion for all $f_{s}>f_{c}$, we need to know the results from continuous conduction mode derived in the next section, but for the present discussion we need only consider the results obtained for $\mathrm{dcm}$ ). If on the other hand we decrease the switching frequency, $M_{m}$ will decrease linearly until the converter enters odd type $(m+1)$ dcm at $f_{b} / f_{0}$. If we continue to decrease the frequency, say down to $f_{a} / f_{0}$, the conversion ratio will stay at a constant value of $1 /(m+1)$. From the foregoing discussion, we see that case $I$ represents an even type $m$ dcm that is bounded between odd type $(\mathrm{m}-1) \mathrm{dcm}$ and odd type $(m+1) \mathrm{dcm}$. Case II on the other hand represents an even type $\mathrm{m}$ dcm that is bounded between an odd type. $(\mathrm{m}+1) \mathrm{dcm}$ and thype $(\mathrm{m}-2) \mathrm{ccm}$; i.e., if we increase $f_{S}$ beyond $1 / m$ the converter enters t type $(\mathrm{m}-2) \mathrm{ccm}$. In case III we have an even type $\mathrm{m} \mathrm{dcm}$ bounded between -type $\mathrm{m} \mathrm{ccm}$ and thype $(\mathrm{m}-2) \mathrm{ccm}$. From the foregoing discussion we see that the region of validity of Eq. (29) is the shaded area shown in Fig. 4.

To determine $f_{b} / f_{0}$ and $f_{c} / f_{0}$ at which operation changes from even type $\mathrm{m}$ dcm to odd type $(\mathrm{m}+1) \mathrm{dcm}$ and odd type $(\mathrm{m}-1) \mathrm{dcm}$ respectively, we equate the conversion ratios of both modes and we get

$$
\begin{aligned}
& \frac{f_{b}}{f_{0}}=\frac{\pi Q}{2 m(m+1)} \\
& \frac{f_{c}}{f_{0}}=\frac{\pi Q}{2 m(m-1)}
\end{aligned}
$$

Referring to Fig. 4, we see that for even type $\mathrm{m} \mathrm{dcm}$ we must have $\mathrm{f}_{\mathrm{b}} / \mathrm{f}_{0} \leq 1 / \mathrm{m}$ (note that $\mathrm{f}_{\mathrm{c}} / \mathrm{f}_{0}$ does not apply to cases II and III), so that from (30a) we get

$$
Q \leq \frac{2(m+1)}{\pi}
$$

This last inequality is very important and states that for even type $m \mathrm{dcm}$ to occur $\mathrm{Q}$ must satisfy (31). For any value of $Q$ larger than $2(\mathrm{~m}+1) / \pi$, even type $\mathrm{m} \mathrm{dcm}$ can not occur. The condition given in (31) covers all three cases $I$, and II and III. If we wish to be particular, we can determine the condition on $Q$ so that we have only case $I$. To do so we require $f_{c} / f_{0} \leq 1 / m$ and we get

$$
\mathrm{Q} \leq \frac{2(\mathrm{~m}-1)}{\pi}
$$

With (31) and (32) we now give the intervals in which even type $\mathrm{m} \mathrm{dcm}$ occurs along with the load conditions:

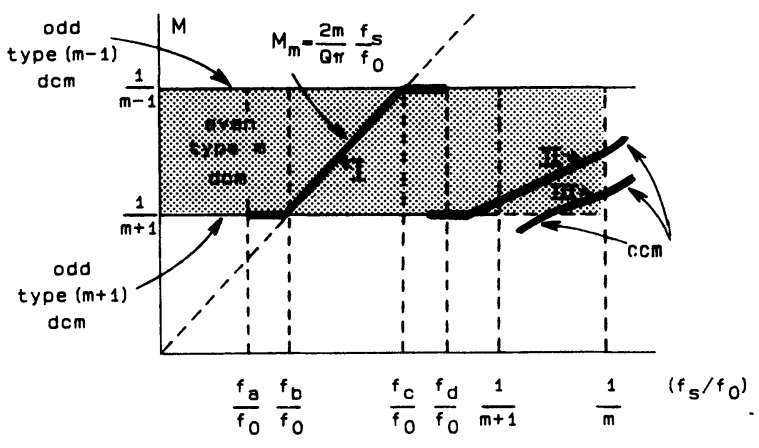

Fig. 4. Boundaries of even type $m \mathrm{dcm}$.

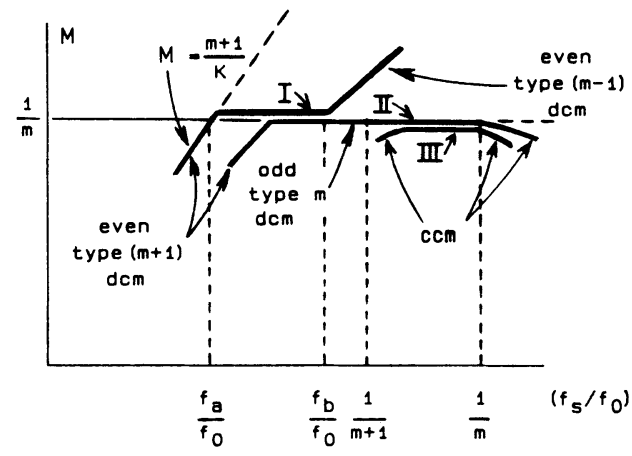

Fig. 5. Boundaries of odd type in dcm.

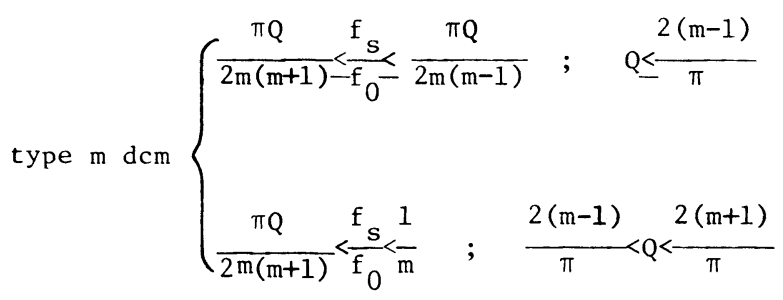

The complete description of even type $\mathrm{m} \mathrm{dcm}$ is given by (33) which states the condition on $Q$ for the occurrence of this mode and the intervals in which it occurs. Comparing (33) to (4) we get:

$$
C_{2}(Q, m)=\frac{\pi Q}{2 m(m+1)}
$$

$$
C_{1}(Q, m)= \begin{cases}\frac{\pi Q}{2 m(m-1)} ; & Q<\frac{2(m-1)}{\pi} \\ & ; \frac{2(m-1)}{\pi}<Q<\frac{2(m+1)}{\pi}\end{cases}
$$

Next we consider operation in an odd type m $\mathrm{dcm}$ which according to (27) has a constant gain of $1 / \mathrm{m}$. As in the case of even type $\mathrm{m} \mathrm{dcm}$ the three separate cases are shown in Fig. 5. The overlap region has been shown split in order to identify the conversion ratio characteristics of each case. 
Case I shows an odd type $\mathrm{m}$ dcm bounded between even type $(m+1) d c m$ and even type $(m-1) d c m$. Case II shows an odd type $\mathrm{m} \mathrm{dcm}$ bounded between even type $(\mathrm{m}+1) \mathrm{dcm}$ and -type $(\mathrm{m}-1) \mathrm{ccm}$. Case III shows an odd type $m \mathrm{dcm}$ bounded between -type $(\mathrm{m}-1) \mathrm{ccm}$ and ttype $(\mathrm{m}-1) \mathrm{ccm}$. Proceeding exactly as before, we can determine the intervals in which odd type $\mathrm{m} \mathrm{dcm}$ occurs along with the conditions on Q. The results will be identical to those obtained for the case of even type $\mathrm{m} \mathrm{dcm}$, so that (33) is valid for the general odd or even type $\mathrm{m} d \mathrm{~cm}$.

In this section we have given the boundary between two discontinuous conduction modes and the intervals in which a general type $\mathrm{m} \mathrm{dcm}$ occurs along with the condition on $Q$.

\section{Physical reason for the occurrence of discontinuous conduction mode}

Now we will show that, when operating in discontinuous conduction mode, the bridge becomes reversed biased when $I_{R}$ ceases to flow. Assume that the converter is operating in even type $\mathrm{m} \mathrm{dcm}$. Referring to Fig. 4 we can clearly see that

$$
M_{m}>\frac{1}{m+1} \text { for } \frac{f_{s}}{f_{0}}>\frac{f_{b}}{f_{0}}
$$

Referring to Fig. 2a, we see that the capacitor voltage $\mathrm{V}_{\mathrm{c}}$ during $\mathrm{I}_{\mathrm{R}}=0$ is $\mathrm{V}_{\mathrm{cm}+1}=$ $-\mathrm{V}_{\mathrm{cl}}=\mathrm{mV}$ (using Eq. (25)), so that the voltage across the bridge is

$$
\mathrm{v}_{\mathrm{B}}=\mathrm{V}_{\mathrm{g}}-\mathrm{v}_{\mathrm{cm}+1}=\mathrm{v}_{\mathrm{g}}-\mathrm{mV}
$$

dividing (35) by $\mathrm{V}$ we get

$$
\frac{\mathrm{V}_{\mathrm{B}}}{\mathrm{V}}=\frac{\mathrm{V}_{\mathrm{g}}}{\mathrm{V}}-\mathrm{m}=\frac{1}{\mathrm{M}_{\mathrm{m}}}-\mathrm{m}
$$

and using (34) we get

$$
\frac{\mathrm{V}_{\mathrm{B}}}{\mathrm{V}}<1
$$

which means that the bridge is reverse biased, and that $I_{R}$ ceases to flow even though $Q 1$ is still $O N$ or $\mathrm{S} 1$ is still closed!

If the converter is operating in odd type $m$ $\mathrm{dcm}$, then by referring to Fig. 5 we have

$$
M_{m}=\frac{1}{m}<\frac{m+1}{K} \text { for } \frac{f_{s}}{f_{0}}>\frac{f_{a}}{f_{0}}
$$

Referring to Fig. $2 b$ we see that the capacitor voltage during $I_{R}=0$ is $v_{c m+1}=-v_{c 1}=$ $\mathrm{KV} / \mathrm{m}$ (where this last step is obtained by substituting $M=1 / \mathrm{m}$ in (20) which is valid for odd type $\mathrm{m} \mathrm{dcm}$ as we11). The voltage across the bridge, $v_{B}=v_{c m+1}-v_{g}$, is

$$
\mathrm{V}_{\mathrm{B}}=\frac{\mathrm{K}}{\mathrm{m}} \mathrm{V}-\mathrm{V}_{\mathrm{g}} \text { or } \quad \frac{\mathrm{V}_{\mathrm{B}}}{\mathrm{V}}=\frac{\mathrm{K}}{\mathrm{m}}-\frac{1}{\mathrm{M}_{\mathrm{m}}} \text {. }
$$

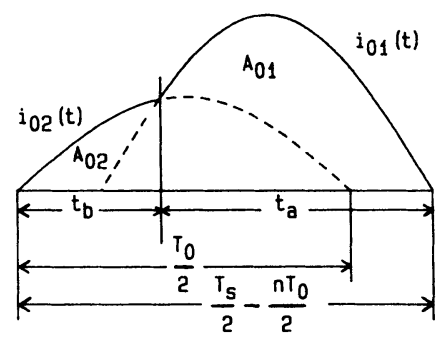

Fig. 6(a). Expansion of the interval $0<t<t_{a}+t_{b}$ in Fig. $3 a$.

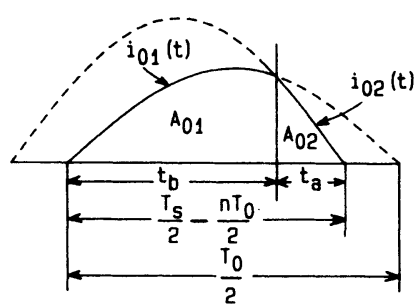

Fig. 6(b). Expansion of the interval $0<t<t_{a}+t_{b}$ in Fig. $3 b$.

Using (38) we get $\frac{\mathrm{V}_{\mathrm{B}}}{\mathrm{V}_{\mathrm{in}}}<1$ so that the bridge is reversed biased again.

\section{ANALYSIS OF THE CONVERSION RATIO IN THE CONTINUOUS CONDUCTION MODE}

Operation in continuous conduction mode depends on which of the following two intervals $\mathrm{f}_{\mathrm{s}} / \mathrm{f}_{0}$ falls in:

$$
\begin{aligned}
\frac{1}{\mathrm{n}+2}<\frac{\mathrm{f}_{\mathrm{s}}}{\mathrm{f}_{0}}<\frac{1}{\mathrm{n}+1} & \\
\frac{1}{\mathrm{n}+1}<\frac{\mathrm{f}_{\mathrm{s}}}{\mathrm{f}_{0}}<\frac{1}{\mathrm{n}} &
\end{aligned}
$$

To determine which interval a given $f_{s} / f_{0}$ falls in, we simply find an even $n$ that satisfies only one of the following two inequalities:

$$
\begin{aligned}
& \mathrm{n}+2>\frac{\mathrm{f}_{0}}{\mathrm{f}_{\mathrm{s}}}>\mathrm{n}+1 \\
& \mathrm{n}+1>\frac{\mathrm{f}_{0}}{\mathrm{f}_{\mathrm{s}}}>\mathrm{n}
\end{aligned}
$$

For instance, if $\mathrm{f}_{\mathrm{S}} / \mathrm{f}_{0}=.3781$, then $\mathrm{f}_{0} / \mathrm{f}_{\mathrm{S}}=2.64$ and only $n=2$ satisfies ( $40 \mathrm{~b})$, so that $1 / 3<\mathrm{f}_{\mathrm{S}} / \mathrm{f}_{0}<1 / 2$. If $\mathrm{f}_{\mathrm{s}} / \mathrm{f}_{0}=.323$, then $f_{0} / f_{S}=3.1$ and only $n=2$ satisfies $(40 a)$, so that $1 / 4<\mathrm{f}_{\mathrm{s}} / \mathrm{f}_{0}<1 / 3$.

Unlike the case of discontinuous conduction mode, the conversion ratio $M$ in the continuous 
conduction mode will be determined numerically. For each of the two types of continuous conduction mode we will determine an equation of the form $F(M, Q, \gamma)=0$ which will be solved numerically for a given load $(Q)$ and switching frequency $(\gamma)$.

\section{type $n \mathrm{ccm}: 1 /(\mathrm{n}+2)<\mathrm{fs}_{\mathrm{s}} / \mathrm{f}_{0}<1 /(\mathrm{n}+1)$}

In this section we will give the most important steps in determining $M$ for ttype $n \mathrm{ccm}$. Referring to Fig. 3a we proceed by equating input and output power of the circuit and obtain

$$
M=\frac{\sum_{m=1}^{n}(-1)^{m_{1}} A_{m}+A_{01}-A_{02}}{\sum_{m=1}^{n} A_{m}+A_{01}+A_{02}}
$$

The output voltage $\mathrm{V}$ is

$$
V=I_{0} R=R \frac{2}{T_{s}}\left(\sum_{m=1}^{n} A_{m}+A_{01}+A_{02}\right)
$$

The recursion relation for the areas $A_{m}$ under the full half cycles of $I_{R}$ can be shown to be

$$
A_{m}=2 C\left(V_{c p}-(2 m-1) V-V_{g}\right)
$$

From (43) we can determine the summation (recall $n$ is even or zero)

$$
\sum_{m=1}^{n}(-1)^{m} A_{m}=-2 n c v
$$

Substituting (44) and (42) into (41) and using definition (9), we get

$$
M=\frac{-2 \mathrm{nCV}+\mathrm{A}_{01}-\mathrm{A}_{02}}{2 \mathrm{VCK}}
$$

To complete the analysis we need to determine the two voltages $v_{c}\left(t_{b}\right)$ and $v_{c}(0)$ and the two currents $i_{01}(t)$ and $i_{02}(t)$ shown in Fig. 3a and Fig. $6 a$.

The currents $i_{01}(t)$ and $i_{02}(t)$ in the interval

$0<t<t_{a}$ shown in Fig. 3a are redrawn in Fig. $6 a$ for clarity.

The peak to peak capacitor voltage is

$$
\begin{aligned}
& \mathrm{CV}_{\mathrm{cp}-\mathrm{p}}=2 \mathrm{CV} \mathrm{cp}=-\sum_{\mathrm{m}=1}^{\mathrm{n}} \mathrm{A}_{\mathrm{m}}(-1)^{\mathrm{m}}+\mathrm{A}_{01}+\mathrm{A}_{02} \\
& \mathrm{~V}_{\mathrm{c}}\left(\mathrm{t}_{\mathrm{b}}\right)=\mathrm{v}_{\mathrm{cp}}-\frac{\mathrm{A}_{01}}{\mathrm{C}}=-\mathrm{MKV}
\end{aligned}
$$

where in the last step we made use (44), (45) and $(46)$. From circuit equations we obtain $i_{02}(t)$ and $\mathrm{A}_{02}$

$$
\begin{gathered}
i_{02}(t)=-\omega_{0} c\left[v_{g}+v+v_{c}(0)\right] \sin \omega_{0} t \\
A_{02}=\int_{0}^{t_{b}} i_{02}(t) d t=c\left[v_{g}+v+v_{c}(0)\right]\left[\cos \omega_{0} t_{b}-1\right]
\end{gathered}
$$

but we have

$$
V_{c}(0)=V_{c}\left(t_{b}\right)-\frac{A_{02}}{C}=-M K V-\frac{A_{02}}{C}
$$

Substituting (50) into (49) and realizing $t_{b}=T_{s} / 2-n_{0} / 2-t_{a}$, we get

$$
A_{02}=C v_{g}\left[M^{2} K-M-1\right]\left[\sec \left(\gamma-\omega_{0} t_{a}\right)-1\right]
$$

$$
i_{02}(t)=\frac{\omega_{0} C V_{g}\left[M^{2} K-M-1\right]}{\cos \left(\gamma-\omega_{0} t_{a}\right)} \sin \omega_{0} t
$$

In the same way we obtain $i_{01}(t)$ and $A_{01}$

$$
\begin{aligned}
& i_{01}(t)=\frac{\omega_{0} C V_{g}\left[1-M+M^{2} K\right]}{\cos \omega_{0} t a} \cdot \sin \left(\omega_{0} t-\gamma\right) \\
& A_{01}=C V_{g}\left[1-M+M^{2} K\right]\left[1-\sec \omega_{0} t_{a}\right]
\end{aligned}
$$

Substituting for $\mathrm{A}_{01}$ and $\mathrm{A}_{02}$ in (45) we obtain

$$
\begin{aligned}
2 M(n+1) & =\left[1+M-M^{2} K\right] \sec \left(\gamma-\omega_{0} t_{a}\right) \\
& -\left[1-M+M^{2} K\right] \sec \omega_{0}{ }_{a}
\end{aligned}
$$

We must also have $i_{01}\left(t_{b}\right)=i_{02}\left(t_{b}\right)$ which gives

$$
\frac{1-M+M^{2} K}{1+M-M^{2} K} \tan \omega_{0} t_{a}=\tan \left(\gamma-\omega_{0} t_{a}\right)
$$

$$
\text { Solving (56) and (55) simultaneously to }
$$
eliminate " $\omega_{0} t_{a}$ " we get

$$
\frac{[n+1]\left[1-M+M^{2} K\right]}{1-M(n+1)^{2}-M K} \cos \gamma=\frac{\sqrt{[M K+n]\left[M^{2}(n+1)^{2}-1\right][n+2-M K]}}{1-M(n+1)^{2}-M K} \sin \gamma
$$

$$
=\frac{\left[1+M-M^{2} K\right][n+1]}{1+M(n+1)^{2}-M K}
$$

The peak capacitor voltage and the peak resonant current are: 


$$
\begin{aligned}
& V_{c p}=V_{g}\left[1+M_{i n}+\frac{M K-1}{n+1}\right] \\
& I_{\text {peak }}=\frac{\omega_{0} C V_{g}}{n+1}\left[M(n+1)^{2}+M K-1\right]
\end{aligned}
$$

In solving (56) and (55) simultaneously to eliminate " $\omega_{0} t$ " we determine:

$$
\begin{aligned}
& \cos \omega_{0}{ }_{a}=\frac{1-M+M^{2} K}{1-M K-M(n+1)^{2}}(n+1) \\
& \sin \omega_{0}{ }_{a}=\frac{\sqrt{[M K+n]\left[M^{2}(n+1)^{2}-1\right][n+2-M K]}}{M K+M(n+1)^{2}-1}
\end{aligned}
$$

Equation (57) is the desired equation from which we can numerically determine the conversion ratio $M$ for a given load and switching frequency. The results are shown in Fig. 8 for $n=0,2$, and 4 which correspond to the intervals $1 / 2<\mathrm{f}_{\mathrm{s}} / \mathrm{f}_{0}<1$, $1 / 4<\mathrm{f}_{\mathrm{s}} / \mathrm{f}_{0}<1 / 3$ and $1 / 6<\mathrm{f}_{\mathrm{S}} / \mathrm{f}_{0}<1 / 5$ respectively. Note that for certain values of $Q, M$ reaches the peak value of $1 /(n+1)$ for $f_{s} / f_{0}<1 /(n+1)$ where $\mathrm{n}=0,2,4$. This happens because operation changes from thype $n \mathrm{ccm}$ to odd type $(n+1) \mathrm{dcm}$.

The boundaries between continuous and discontinuous conduction mode are determined in Section 6 .

\section{-type $n \mathrm{ccm}: 1 /(\mathrm{n}+1)<\mathrm{f}_{\mathrm{s}} / \mathrm{f}_{0}<1 / \mathrm{n}$}

Referring to Fig. 3b we proceed as before by equating input and output power and obtain

$$
M=\frac{-\sum_{m=1}^{n} A_{m}(-1)^{m}+A_{01}-A_{02}}{\sum_{m=1}^{n} A_{m}+A_{01}+A_{02}}
$$

For the output voltage we have

$$
V=\left\langle\left|I_{R}(t)\right|\right\rangle R=\frac{2}{T_{s}} R\left[\sum_{m}^{n} A_{m}+A_{01}+A_{02}\right]
$$

The recursion relation for the areas $A_{m}$ under the full half cycles can be shown to be

$$
A_{m}=2 c\left[v_{g}-(2 m-1)-v_{c l}\right]
$$

where $\mathrm{V}_{\mathrm{cl}}$, as shown in Fig. $3 \mathrm{~b}$, is the capacitor voltage at the beginning of the first full half cycle. Next we determine the summation in (61), which for $\mathrm{n}=$ even gives:

$$
\sum_{m=1}^{n} A_{m}(-1)^{m}=-2 n C V
$$

Substituting (64) and (62) into (61) and making use of definition (9) we get

$$
M=\frac{2 \mathrm{nCV}+\mathrm{A}_{01}-\mathrm{A}_{02}}{2 \mathrm{CVK}}
$$

To complete the analysis we need to determine $i_{01}(t)$ and $i_{02}(t)$. These are determined in the same way as in the previous case:

$$
\begin{aligned}
& i_{01}(t)=\frac{V_{g} \omega_{0} C\left[1-M-M^{2} K\right] \sin \omega_{0} t}{\cos \left(\gamma-\omega_{0} t_{a}\right)} \\
& A_{01}=C v_{g}\left[1-M-M^{2} K\right]\left[\sec \left(\gamma-\omega_{0} t_{a}\right)-1\right]
\end{aligned}
$$

$$
\begin{aligned}
& i_{02}(t)=\frac{v_{g} \omega_{0} C\left[1+M+M^{2} K\right]}{\cos \omega_{0} t a} \sin \left(\gamma-\omega_{0} t\right) \\
& A_{02}=v_{g} C\left[1+M+M^{2} K\right]\left[\sec \omega_{0} t_{a}-1\right]
\end{aligned}
$$

Substituting $\mathrm{A}_{02}$ and $\mathrm{A}_{01}$ into (65) we obtain:

$$
\left(1+M+M^{2} K\right) \sec \omega_{0} t_{a}-\left(1-M-M^{2} K\right) \sec \left(\gamma-\omega_{0} t_{a}\right)=2 M(n+1) \quad(70)
$$

Requiring $i_{02}\left(t_{b}\right)=i_{01}\left(t_{b}\right)$ we obtain

$$
\frac{1+M+M^{2} K}{1-M-M^{2} K} \tan \omega_{0} t_{a}=\tan \left(\gamma-\omega_{0} t_{a}\right)
$$

We solve (70) and (71) to eliminate " $\omega_{0} t_{a}$ " and we get :

$$
\begin{aligned}
& \frac{[n+1]\left[1+M+M^{2} K\right]}{1+M(n+1)^{2}+M K} \cos \gamma+\frac{\sqrt{[M K-n]\left[1-M^{2}(n+1)^{2}\right][n+2+M K]}}{1+M(n+1)^{2}+M K} \sin \gamma \\
& \quad=\frac{\left(1-M-M^{2} K\right)(n+1)}{1-M(n+1)^{2}+M K}
\end{aligned}
$$

The peak capacitor voltage is

$$
v_{c p}= \begin{cases}V_{g} M K & n=0 \\ V_{g}\left[1-3 M+\frac{1+M(n+1)^{2}+M K}{n+1}\right], & n \text { even }\end{cases}
$$

As in the previous case (72) is the desired equation from which we can determine numerically the conversion ratio $M$ for -type $\mathrm{n} \mathrm{cm}$ for a given load 


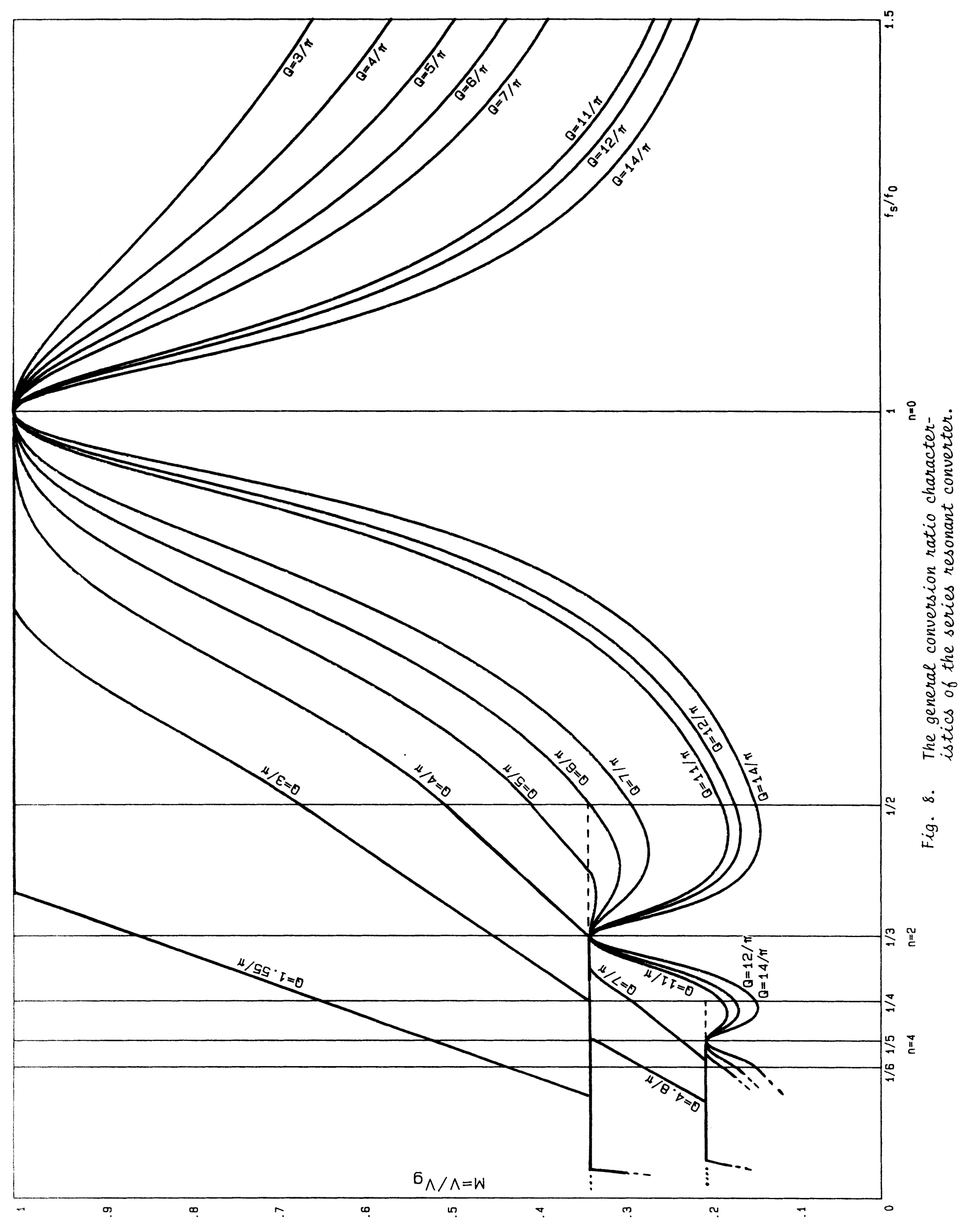


and switching frequency. The results are shown in Fig. 8 for $\mathrm{n}=0,2$, and 4 which correspond to the intervals $\mathrm{f}_{\mathrm{s}} / \mathrm{f}_{0}>1,1 / 3<\mathrm{f}_{\mathrm{s}} / \mathrm{f}_{0}<1 / 2$ and $1 / 5<\mathrm{f}_{\mathbf{s}} / \mathrm{f}_{0}<1 / 4$ respectively. The interval $\mathrm{f}_{\mathrm{s}} / \mathrm{f}_{0}>1$ corresponds to exciting the circuit above resonance and has no discontinuous conduction mode. In the intervals $1 / 3<\mathrm{f}_{\mathrm{s}} / \mathrm{f}_{0}<1 / 2$ and

$1 / 5<\mathrm{f}_{\mathrm{s}} / \mathrm{f}_{0}<1 / 4$ we see that for certain values of $Q$ operation changes from continuous to discontinuous conduction mode. These boundaries between continuous and discontinuous mode will be given in Section 6 . We also note the occurrence of second and third resonant peaks at $f_{s} / f_{0}=1 / 3$ and $f_{s} / f_{0}=1 / 5$. There are in fact, an infinite number of these resonant peaks located at $\mathrm{f}_{\mathrm{s}} / \mathrm{f}_{0}=1,1 / 3,1 / 5, \ldots$, $1 / \mathrm{m} \ldots$... (m = odd) with the maximum value of $M$ at these peaks being equal to $M_{\text {peak }}=1,1 / 3,1 / 5, \ldots$ $1 / \mathrm{m}$ ( $\mathrm{m}=$ odd) respectively. Of course, in reality these results are valid only for switching times that are short compared to the output load time constant.

The peak resonant current is

$\dot{I}_{\text {peak }}=\left\{\begin{array}{l}\omega_{0} C V_{g}[1-M+M K] ; 1-M-M^{2} K<0 \\ \omega_{0} C V_{g} \sqrt{M K\left(1-M^{2}\right)(M K+2)} ; 1-M-M^{2} K>0 \\ \omega_{0} C V_{g}\left[\frac{1}{n+1}+M\left(n-1+\frac{K}{n+1}\right)\right] \\ n \neq 0\end{array}\right.$

The reason $v_{c p}$ for $n=0$ is different from $\mathrm{n} \neq 0 \mathrm{c}$ an be seen from Fig. 3b. For -type $\mathrm{n} \mathrm{ccm}$ $v_{c p}$ occurs at the end of the first full half cycle of $I_{R}$ which for $n=0$ does not exist and consequent$1 y V_{c p}=v_{c}\left(t_{a}+t_{b}\right)=M K V_{g}$. For ttype $n c c m V_{c p}$ occurs at the end of $i_{01}(t)$ which is always present, even when $n=0$. This is the same reason for $I_{\text {peak }}$ to be different for $n=0$ and $n \neq 0$. In the case of $I_{\text {peak, }}$, however, we see from Fig. 7 that for -type $0 \mathrm{ccm}$, I peak depends on the intersection of $i_{01}(t)$ and $i_{02}(t)$. If $i_{01}(t)$ and $i_{02}(t)$ intersect after the occurrence of the peak of $i_{01}(t)$, then $I_{\text {peak }}$ is the same as the peak of $i_{01}(t)$. If $i_{01}(t)$ and $i_{02}(t)$ intersect before the occurrence of the peak of $i_{01}(t)$, then $I_{\text {peak }}=i_{01}\left(t_{b}\right)$. It can be shown that this break point occurs for $1-M-M^{2} K=0$ It can also be shown that $0<\omega_{0} t_{a}<\pi / 2$ for -type $n \mathrm{ccm}(\mathrm{n}=0,2,4 \ldots)$, so that the peak of $i_{02}(t)$ never occurs.
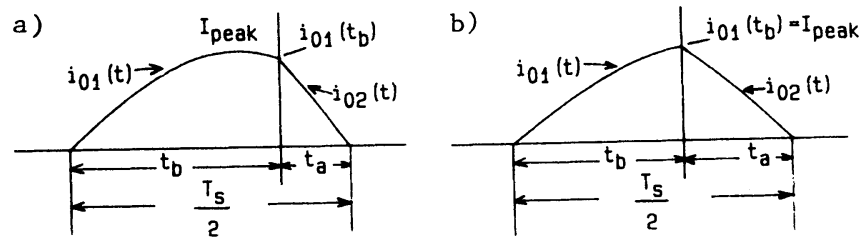

Fig. 7. (a) I peak for -type $0 \mathrm{ccm}$ for $1-M-M^{2} K<0$ and (b) for $1-M-M^{2} K>0$.

\section{BOUNDARY BETWEEN DISCONTINUOUS AND} CONTINUOUS CONDUCTION MODE

The conversion ratio characteristics for the general continuous and discontinuous conduction modes are shown in Fig. 9. The line $M=1 /(n+1)$ is the boundary between discontinuous conduction mode and t type $n$ and -type $n$ continuous conduction modes. In this section we will analyze the range of critical values of $Q$ which determine the mode of operation of the converter. Before going into the analysis, let us study the results given in Fig. 9. The two shaded regions in Fig. 9 are determined by the range of critical values of $Q$.

In region I the conversion ratio characteristics belong to the range of values of $\mathrm{Q} \varepsilon[2 n / \pi, 2(n+1) / \pi]$. The dashed line is the boundary between even type $n \mathrm{dcm}$ and -type $n \mathrm{ccm}$. This is precisely case III discussed in Fig. 4. In the interval $1 /(n+1)<f_{s} / f_{0}<1 / n$, for this range of values of $Q$, operation changes from -type $\mathrm{n} \mathrm{ccm}$ to even type $\mathrm{n}$ dcm as we increase $\mathrm{f}_{\mathbf{s}} / \mathrm{f}_{0}$ from $1 /(n+1)$ to $1 / n$. Upon careful examination of Fig. 9 , we realize that because of the periodic nature of the intervals, the converter will be in continuous conduction mode for all $\mathrm{f}_{\mathbf{S}} / \mathrm{f}_{0}>1 / \mathrm{n}$ and in discontinuous conduction mode for all $\mathrm{f}_{\mathrm{s}} / \mathrm{f}_{0}<1 /(\mathrm{n}+1)$. Moreover, for all these values of $Q$ the conversion ratio will be $1 /(n+1)$ in the interval $1 /(n+2)<f_{s} / f_{0}<1 /(n+1)$ which is the case of overlapping characteristics as discussed in Fig. 5 (case II). We have the following now:

$\frac{2 n}{\pi}<Q<\frac{2(n+1)}{\pi}\left\{\begin{array}{l}\frac{f_{s}}{f_{0}}>\frac{1}{n} \\ \frac{Q \pi}{2 n(n+1)}<\frac{f_{s}}{f_{0}}<\frac{1}{n} \quad \text { Even type } n d c m \\ \frac{1}{n+1}<\frac{f}{f_{0}}<\frac{Q \pi}{2 n(n+1)} \quad \text {-type } n c c m \\ \frac{f_{s}}{f_{0}}<\frac{1}{n+1} \\ \text { dcm })\end{array}\right.$

Compare the second interval in (75) to the second interval given in (33).

Region II corresponds to the range of values of $Q \varepsilon[2(n+1) / \pi, 2(n+2) / \pi]$. This is the same as case III shown in Fig. 5. For these values of $Q$ we have:

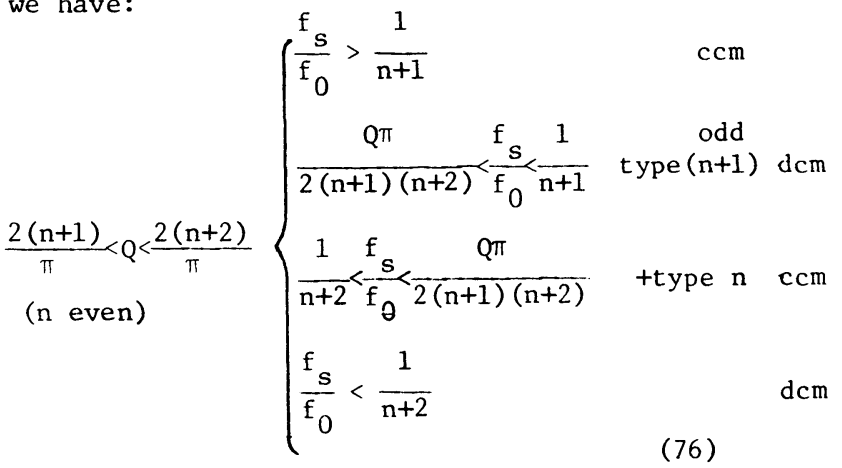




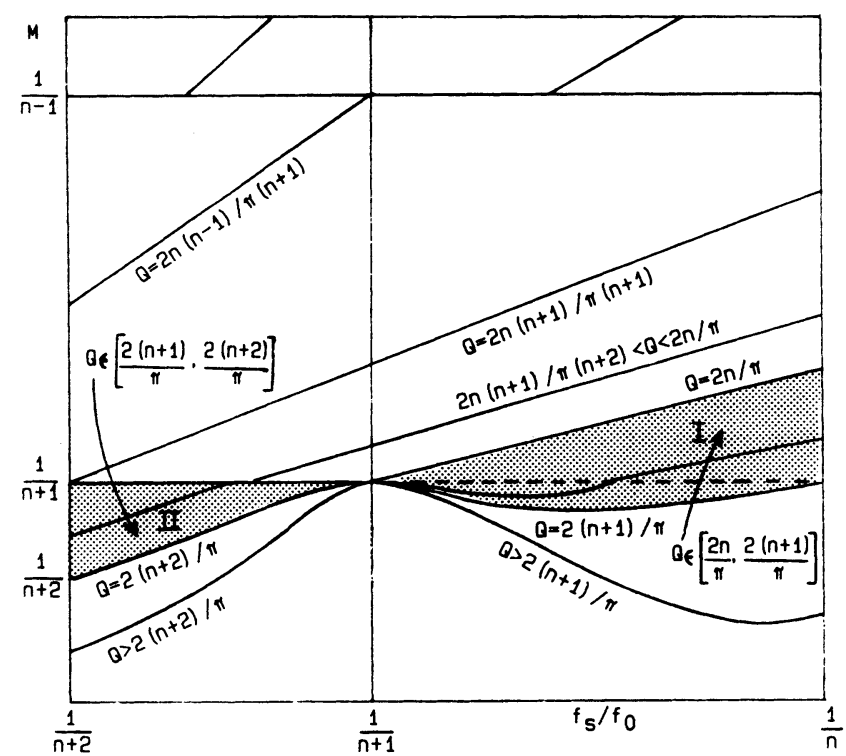

Fig. 9. General boundaries between continuous and discontinuous conduction modes, and the range of critical values of $Q$.

To determine which of the two regions a given $Q$ belongs to, we determine an even " $n$ " that satisfies only one of the two following inequalities:

$\mathrm{n}+2>\frac{\mathrm{Q} \pi}{2}>\mathrm{n}+1 \rightarrow$ Region II

$$
\mathrm{n}+\mathrm{l}>\frac{\mathrm{Q} \pi}{2}>\mathrm{n} \quad \rightarrow \text { Region } \mathrm{I}
$$

If $Q=10$, for instance, then only $(77 a)$ is satisfied for $n=14$, and passage from continuous to discontinuous conduction mode is given by (76). If $Q=9$, then only (77b) is satisfied for $\mathrm{n}=14$ and passage from continuous to discontinuous conduction mode is given by (75).

For a given $f_{S} / f_{0}$ the critical values of $Q$ depend which interval $f_{S} / f_{0}$ falls in:

$$
\begin{aligned}
& \frac{1}{n+2}<\frac{f}{f_{0}}<\frac{1}{n+1}\left\{\begin{array}{l}
Q<\frac{f}{f_{0}} \frac{2(n+1)(n+2)}{\pi} \\
Q>\frac{f}{f_{0}} \frac{2(n+1)(n+2)}{\pi}
\end{array} \text { ttype } n c c m\right.
\end{aligned}
$$

The results just given are derived by studying the radicals in equations (57) and (72). In the interval $1 /(\mathrm{n}+1)<\mathrm{f}_{\mathrm{s}} / \mathrm{f}_{0}<1 / \mathrm{n}$ we see from (72) that we must have

$$
M K \geq n \text { and } M \leq \frac{1}{n+1}
$$

Since in this interval the maximum value of $M$, for the -type $n$ continuous conduction mode, is $1 /(n+1)$, we get from (79)

$$
\begin{gathered}
K \geq n(n+1) \text { or } \frac{1}{n+1} \leq \frac{f_{s}}{f_{0}} \leq \frac{Q \pi}{2 n} \cdot \frac{1}{(n+1)} \text { or } \\
Q \geq \frac{f_{s}}{f_{0}} \cdot \frac{2 n(n+1)}{\pi}
\end{gathered}
$$

Since the maximum value of $\mathrm{f}_{\mathrm{s}} / \mathrm{f}_{0}$ in this interval is $1 / \mathrm{n}$, then we see from the last inequality in $(80)$ that in order to have -type $n$ $\mathrm{ccm}$ in the entire interval $1 /(\mathrm{n}+1)<\mathrm{f}_{\mathrm{s}} / \mathrm{f}_{0}<1 / \mathrm{n}$ we must have $Q \geq 2(n+1) / \pi$. This is the region below region I in Fig. 9. For values of $Q<2(n+1) / \pi$ we have continuous conduction mode over an interval given by $(80)$ which is more restricted than $1 /(n+1)<f_{s} / f_{0}<1 / n$. However, since the minimum value of $\mathrm{f}_{\mathbf{s}} / \mathrm{f}_{0}$ in this interval is $1 /(n+1)$, we must have $Q>2 n / \pi$ for continuous conduction mode as required by $(80)$. The values of $2 n / \pi<Q<2(n+1) / \pi$ define region $I$, and the results in (75) follow.

From ( 80$)$ and the preceeding discussion, we can see that $B_{2}(Q, n)$ in Table 1 of Section 2 is given by

$$
B_{2}(Q, n)=\left\{\begin{array}{lll}
\frac{Q \pi}{2 n(n+1)} & ; & \frac{2 n}{\pi}<Q<\frac{2(n+1)}{\pi} \\
\frac{1}{n} & ; & Q>\frac{2(n+1)}{\pi}
\end{array}\right.
$$

For the interval $1 /(n+2)<f_{S} / f_{0}<1 /(n+1)$, we study the radical in Eq. (57), from which we get

$$
M K>n+2 \text { and } M \leq \frac{1}{n+1}
$$

Since in this interval the maximum value of $M$ in the thype $n$ continuous conduction mode is $1 /(n+1)$, we get from (81)

$K \geq(n+1)(n+2)$ or $Q \geq \frac{f_{S}}{f_{0}} \cdot \frac{2}{\pi}(n+1)(n+2)$ or

$$
\frac{1}{n+2}<\frac{f_{s}}{f_{0}}<\frac{Q \pi}{2} \cdot \frac{1}{(n+1)(n+2)}
$$

The maximum value of $\mathrm{f}_{\mathrm{s}} / \mathrm{f}_{0}$ in this interval is $1 /(n+1)$ so that we see from $(82)$, in order to have continuous conduction mode in the entire interval 
$1 /(n+2)<f_{s} / f_{0}<1 /(n+1)$, we must have $Q>2(n+2) / \pi$. The range of values $Q>2(n+2) / \pi$ defines the region below region II. For values of $Q<2(n+2) / \pi$ we will have continuous conduction mode in an interval given by (82) which is more restricted than $1 /(n+2)<f_{s} / f_{0}<1 /(n+1)$. However, since the minimum value of $f_{s} / f_{0}$ in this interval is $1 /(n+2)$ we must have $Q>2(n+1) / \pi$ for continuous conduction as required by $(82)$. The range of values of $2(n+1) / \pi<Q<2(n+2) / \pi$ defines region II, and the results in $(7 \overline{6})$ follow.

From (82) and the preceeding discussion we can see that $B_{1}(Q, n)$ in Table 1 of Section 2 is given by

$$
B_{1}(Q, n)=\left\{\begin{array}{lll}
\frac{Q \pi}{2(n+1)(n+2)} & ; & \frac{2(n+1)}{\pi} Q<\frac{2(n+2)}{\pi} \\
\frac{1}{n+1} & ; & Q>\frac{2(n+2)}{\pi}
\end{array}\right.
$$

The results in (78) follow directly from (75) and (76). From (78) we can see that there can be no continuous conduction mode for $Q<2 n / \pi$ in the interval $1 /(n+1)<f_{s} / f_{0}<1 / n$, and for $Q<2(n+1) / \pi$ there can be no continuous conduction mode in $1 /(n+2)<f_{s} / f_{0}<1 /(n+1)$.

\section{OPERATION IN THE SPECIAL CASE WHEN Q1 AND Q2 ARE OFF SIMULTANEOUSLY}

Until now we assumed that Q1 and Q2 were allowed to conduct for the entire duration of $\mathrm{T}_{\mathbf{s}} / 2$. If conduction is inhibited by switching Q1 (or Q2) OFF before the end of $\mathrm{T}_{\mathrm{s}} / 2$, the converter will be forced to operate with a finite number of allowed continuous and discontinuous conduction modes over the entire range $f_{s} / f_{0} \varepsilon[0, \infty]$. To illustrate this, let us refer to Fig. 2a and assume $\mathrm{n}=6$ for a given $\mathrm{Q}$ and $\mathrm{f}_{\mathrm{s}} / \mathrm{f}_{0}$. In Sections 2,3 , and 4 we showed that although the transistors were $\mathrm{ON}$ during the entire period $\mathrm{T}_{s} / 2, \mathrm{I}_{R}$ became discontinuous because the output bridge rectifier became reverse biased. Now we ask what happens if under the same operating conditions the transistors are switched OFF after conducting the current $i_{1}(t)$. The current $i_{2}(t)$ which is carried by the diode (D1 or D2) will flow because we can not switch OFF D1 or D2. The current $i_{3}(t)$ will not be able to flow, however, because Q1 is switched $\mathrm{OFF}$ and the circuit will be forced to operate in type $2 \mathrm{dcm}$ instead of type 6 . Moreover, we see that in the entire range $\mathrm{f}_{\mathbf{s}} / \mathrm{f}_{0} \varepsilon[0, \infty]$ the allowed modes of operation are type $1 \mathrm{dcm}$, type $2 \mathrm{dcm}$ and + type $0 \mathrm{ccm}$. To illustrate further, if we assume for the same $Q$ and $f_{s} / f_{0}$, the transistors are switched OFF after conducting the current $i_{3}(t)$, the converter will be forced to operate in type 4 $\mathrm{dcm}$ instead of type $6 \mathrm{dcm}$. In this case the allowed modes of operation in the entire range $f_{s} / f_{0} \in[0, \infty]$ are type $1 \mathrm{dcm}$ through type $4 \mathrm{dcm}$, \pm type $2 \mathrm{ccm}$ and \pm type $0 \mathrm{ccm}$.

We see from the preceeding discussion that when $Q 1$ and $Q 2$ are OFF simultaneously, the conversion ratio characteristics in the interval $0<\mathrm{f}_{\mathbf{s}} / \mathrm{f}_{0}<1 / 2$ will be different from that in

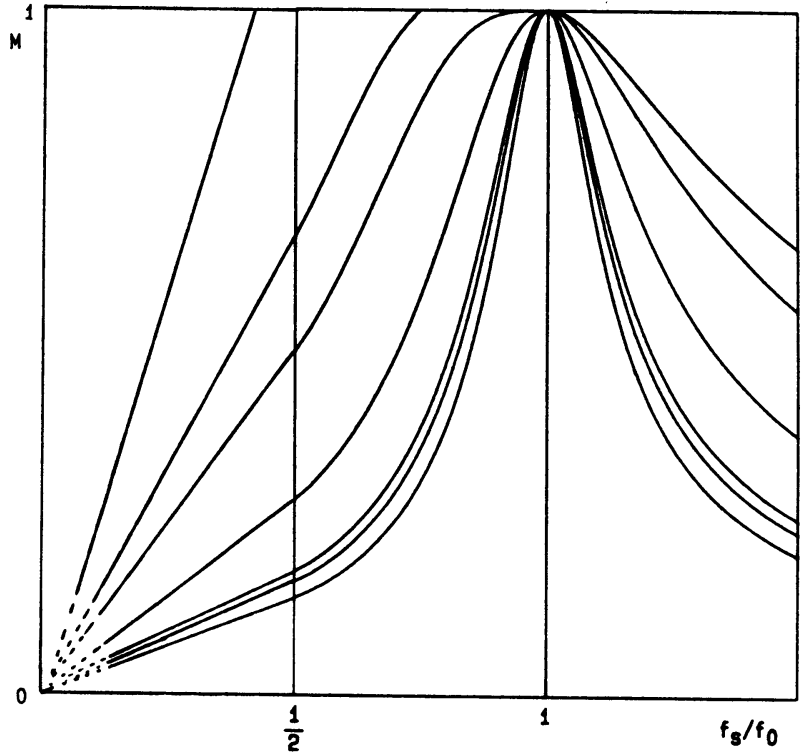

Fig.10. The conversion ratio characteristics in the special case when $\mathrm{Q} 1$ and $\mathrm{Q} 2$ are allowed to conduct only once.

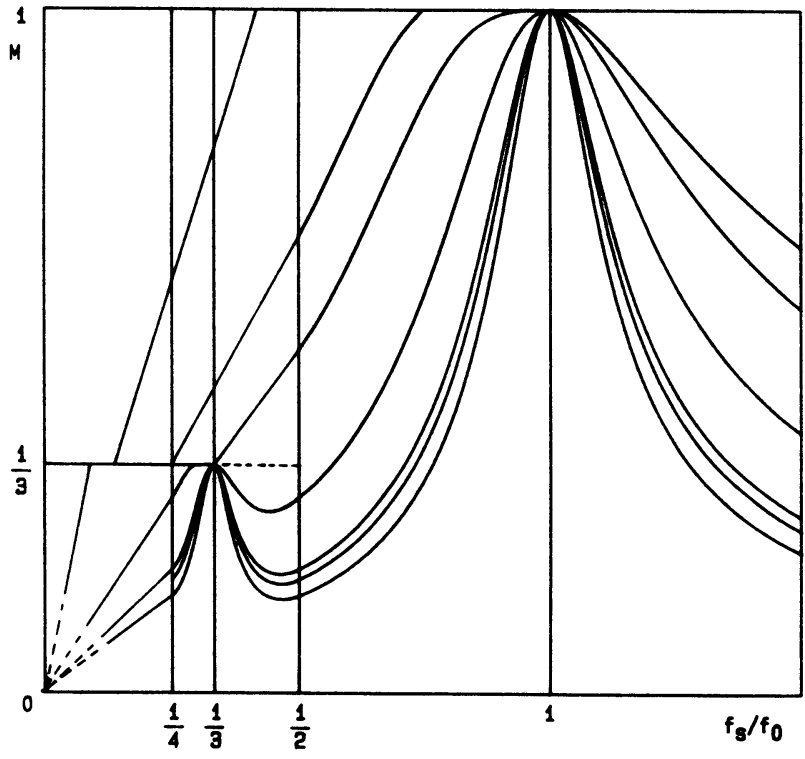

Fig. 11. The conversion ratio characteristics in the special case when Q1 and Q2 are allowed to conduct at most twice.

Fig. 8. In the interval $\mathrm{f}_{\mathrm{S}} / \mathrm{f}_{0}>1 / 2$ the conversion ratio characteristics will not be affected because in this interval Q1 and Q2 conduct only once.

Fig. 10 shows the conversion ratio characteristics when Q1 and Q2 are allowed to conduct only once in the period $\mathrm{T}_{\mathrm{s}} / 2$. Since the only allowed modes of operation in this case are type $1 \mathrm{dcm}$, type $2 \mathrm{dcm}$, and \pm type $0 \mathrm{ccm}$, we can not have the other resonant peaks at $\mathrm{f}_{\mathrm{s}} / \mathrm{f}_{0}=1 / 3,1 / 5, \ldots$ as 
shown in Fig. 8. In the entire interval $0<\mathrm{f}_{\boldsymbol{s}} / \mathrm{f}_{0}<1 / 2 \quad \mathrm{M}$ will be given by (23) for type 2 $\mathrm{dcm}$ and (27) for type $1 \mathrm{dcm}$. Moreover, we notice that the lower bound of the frequency interval in which type $2 \mathrm{dcm}$ can occur is zero instead of $C_{2}(Q, 2)=\pi Q / 12$ as given by (33). This is obvious because $f_{s} / f_{0}=C_{2}(Q, 2)$ is the boundary between type $2 \mathrm{dcm}$ and type $3 \mathrm{dcm}$ which we can not have since we have constrained the converter to operate with a maximum of type $2 \mathrm{dcm}$.

In general if the transistor is allowed to conduct at most only $j$ number of times in the period $\mathrm{T}_{\mathrm{s}} / 2$, the maximum allowed discontinuity is type $2 j \mathrm{dcm}$ and consequently $\mathrm{C}_{2}(Q, 2 j)=0$.

Fig. 11 shows the conversion ratio characteristics when $\mathrm{Q} 1$ and $\mathrm{Q} 2$ are allowed to conduct only twice in the period $\mathrm{T}_{s} / 2$. In this case the maximum allowed discontinuity is type 4 $\mathrm{dcm}$ and $C_{2}(Q, 4)=0$. The $M$ for type $2 \mathrm{dcm}$ will now be sandwiched between $M=1 / 3$ and $M=1$ because of the occurrence of type $3 \mathrm{dcm}$. In addition to the first peak at $\mathrm{f}_{\mathrm{s}} / \mathrm{f}_{0}=1$, we also have the second resonant peak at $\mathrm{f}_{\mathbf{s}} / \mathrm{f}_{0}=1 / 3$ but not any other. It is clear from the above discussion that if we allow Q1 and Q2 to conduct at most $j$ times in the period $\mathrm{T}_{\mathrm{s}} / 2$, we will have only $j$ resonant peaks at $\mathrm{f}_{\mathrm{s}} / \mathrm{f}_{0}=1,1 / 3, \ldots 1 /(2 \mathrm{j}-1)$.

This completes the D.C. analysis of the series resonant converter in the general discontinuous and continuous conduction modes.

\section{EXPER IMENTAL RESULTS}

A resonant converter was built with the resonant frequency selectable either at $f_{0}=35.7 \mathrm{kHz}$ or $\mathrm{f}_{0}=157 \mathrm{kHz}$. The output transformer was eliminated in order to avoid extra parasitic losses. The voltages $V_{T}$ and $V_{B}$ shown in Fig. 1a were measured and the conversion ratio $M$ was determined by taking the ratio of $V_{T}$ to $V_{B}$, so that

$$
M=\frac{v_{T}}{V_{B}}=\frac{v_{g}-v_{s}}{V+2 v_{D}} \simeq \frac{v_{g}}{V+2 v_{D}}
$$

$\mathrm{V}_{\mathrm{S}}$ is the voltage across $\mathrm{S} 1$ or $\mathrm{S} 2$ and varies between $V_{\text {sat }}$ and $-V_{D 1}$ depending on the direction of the current $I_{R}$. Normally $v_{g}$ is much greater than either $V_{\text {sat }}$ or $V_{D 1}$, and the approximation in (83) is good. Accounting for the voltage drops in the output bridge rectifier is slightly more complicated and requires modification of the $Q$. This is done by considering the power dissipated at the input terminals of the bridge rectifier:

$$
P_{\text {out }}=2 V_{D} \frac{\left(V_{B}-2 v_{D}\right)}{R}+\frac{\left(v_{B}-2 v_{D}\right)^{2}}{R}
$$

The first term in (84) represents the losses in the bridge and the second term is the power delivered to the load R. Rearranging (84) we get

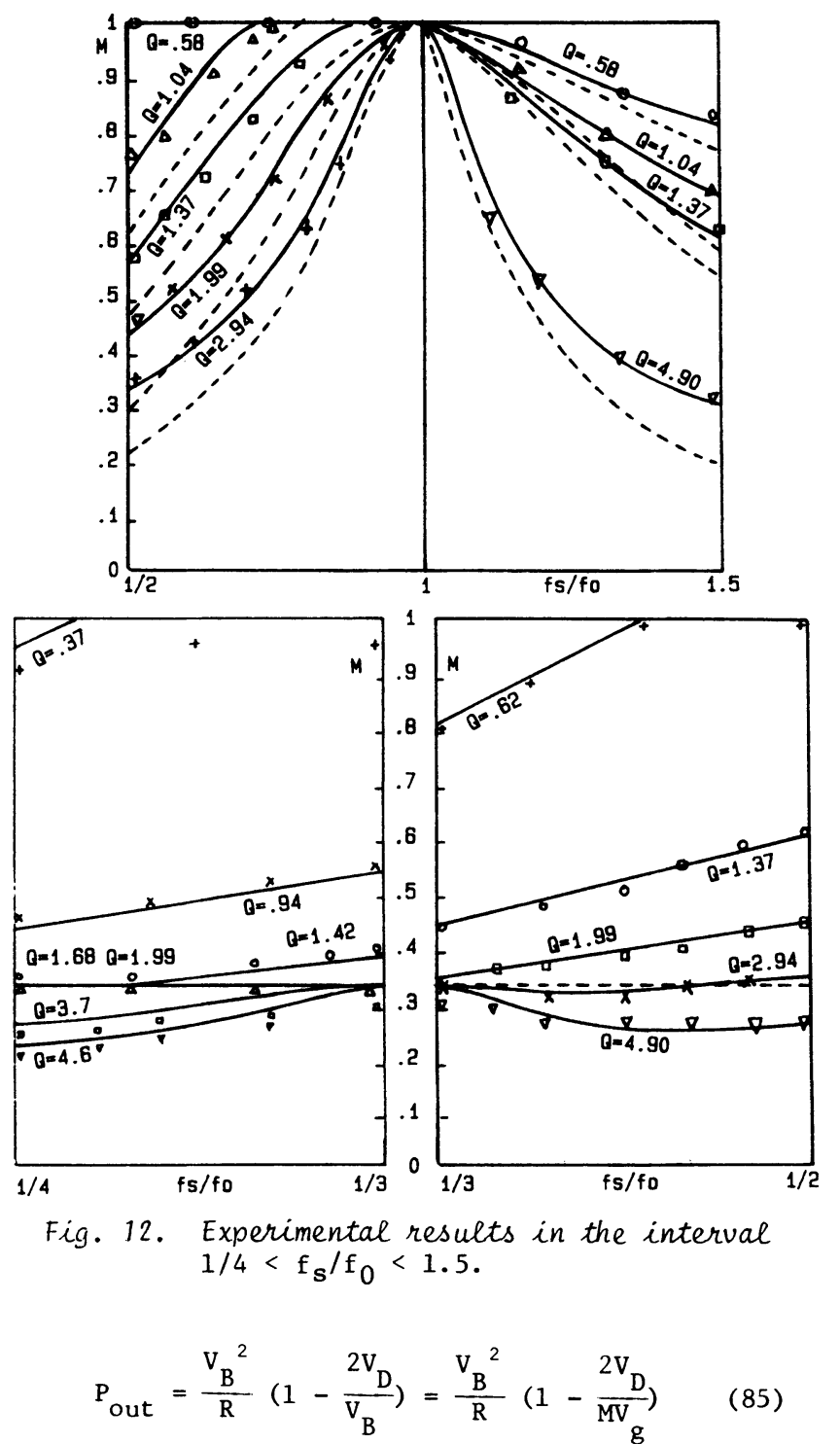

Eq. (85) implies that when we consider the conversion ratio $M=v_{g} / V_{B}$, then $R$ and $Q$ must be modified according to

$$
\mathrm{R}=\frac{\mathrm{R}}{1-2 \mathrm{~V}_{\mathrm{D}} / \mathrm{MV}_{\mathrm{g}}} \text { or } \mathrm{Q}=\mathrm{Q}\left[1-\frac{2 \mathrm{~V}_{\mathrm{D}}}{\mathrm{MV}}\right]
$$

To determine $M$ for even type $n$, with $Q$ modified, we substitute (86) in (23) and obtain

$$
M=\frac{2 n}{Q \pi} \frac{f_{s}}{f_{0}}+\frac{2 V_{D}}{V_{g}}
$$

The conversion ratio of the odd type $\mathrm{n} d \mathrm{dcm}$ remains unaffected by this modification of $Q$. For ttype $\mathrm{n} \mathrm{ccm}$ and -type $\mathrm{n} \mathrm{ccm} \mathrm{the} \mathrm{correction} \mathrm{for} \mathrm{Q}$ to determine $M$ is done numerically. Experimental results are shown in Fig. 12a,b,c. In Fig. 12a the dashed lines indicate the conversion ratio characteristics without modifying $Q$ and the solid 
lines after modifying $Q$ as in (86). The boundary conditions given in (75), (76) and (78) can be easily modified by changing $Q$ to $Q\left[1-2 V_{D}(n+1) / V_{g}\right]$ as can be seen from (86) in which we let $M=1 /(n+1)$.

Figs. 13a,b,c show how operation changes from type $1 \mathrm{dcm}$ to type $2 \mathrm{dcm}$ to -type $2 \mathrm{ccm}$ as we change the load while operating at a fixed switching frequency. In Fig. 13a we see that although the diodes D1 and D2 are present, they do not conduct because the load $R$ is not small enough. This can be seen from (33) in which if we let $\mathrm{m}=2$, we require $Q \geq 4 \mathrm{f}_{\mathrm{s}} / \pi \mathrm{f}_{0}$ for type $2 \mathrm{dcm}$ to occur. When the $Q$ is modified according to (86), this condition becomes $Q \geq 4 \mathrm{f}_{\mathrm{s}} / \pi \mathrm{f}_{0}\left(1-2 \mathrm{~V}_{\mathrm{D}} / \mathrm{V}_{\mathrm{g}}\right)$. The operating conditions for Fig. 13a are

$$
\begin{aligned}
& \mathrm{f}_{\mathrm{S}}=13.9 \mathrm{kHz} \quad \mathrm{L}=.197 \mathrm{mH} \quad \mathrm{V}_{\mathrm{g}}=14 \mathrm{~V} \\
& \mathrm{f}_{0}=35.7 \mathrm{kHz} \quad \mathrm{R}=89 \Omega \quad \mathrm{V}_{\mathrm{D}}=.7 \mathrm{~V} \\
& \frac{\mathrm{f}_{\mathrm{s}}}{\mathrm{f}_{0}}=.389 \rightarrow \mathrm{n}=2 \text { and } 1 / 3<\mathrm{f}_{\mathrm{s}} / \mathrm{f}_{0}<1 / 2 \\
& \mathrm{Q}=.496, \frac{4 \mathrm{f}_{\mathrm{s}}}{\pi \mathrm{f}_{0}} \frac{1}{1-2 \mathrm{~V}_{\mathrm{D}} / \mathrm{V}_{\mathrm{g}}}=.55
\end{aligned}
$$

We see then from (88) that $Q$ does not satisfy the condition for type $2 \mathrm{dcm}$ to occur and as a result the diodes D1 and D2 do not conduct.

If we now change the load to $R=27.0 \Omega$, the diodes D1 and D2 begin to conduct and operation changes to type $2 \mathrm{dcm}$ as shown in Fig. 13b. The transistors Q1 and Q2, however, do not conduct for the second time in $\mathrm{T}_{\mathrm{S}} / 2$ even though they are still ON. This can be seen from (78) in which if we let $\mathrm{n}=2$, we require $\mathrm{Q}>12 \mathrm{f}_{\mathrm{s}} / \mathrm{f}_{0} \pi$ for -type $2 \mathrm{ccm}$ to occur. When $Q$ is modified according to (86), this condition becomes for $\mathrm{n}=2$

$\mathrm{Q} \geq 12 \mathrm{f}_{\mathrm{s}} / \mathrm{f}_{0} \pi\left(1-6 \mathrm{~V}_{\mathrm{D}} / \mathrm{V}_{\mathrm{g}}\right)$. For the operating conditions in Fig. $13 \mathrm{~b}$ we have

$$
\mathrm{R}=27 . \Omega, Q=1.64, \frac{12 \mathrm{f}_{\mathrm{s}}}{\pi \mathrm{f}_{0}\left(1-6 \mathrm{~V}_{\mathrm{D}} / \mathrm{V}_{\mathrm{g}}\right)}=2.13
$$

We see then from (89) that $Q$ does not satisfy the condition for -type $2 \mathrm{ccm}$ to occur and as a result $\mathrm{Q} 1$ and $\mathrm{Q} 2$ do not conduct for the second time in $\mathrm{T}_{\mathrm{S}} / 2$.

If we change the load further to $R=11 \Omega$ then $Q=4.0>2.13$, and the condition for -type 2 $\mathrm{ccm}$ to occur is satisfied. This is seen in Fig. 13c in which we see the transistors $Q 1$ and $Q 2$ conducting for the second time in the interval $\mathrm{T}_{\mathrm{S}} / 2$.

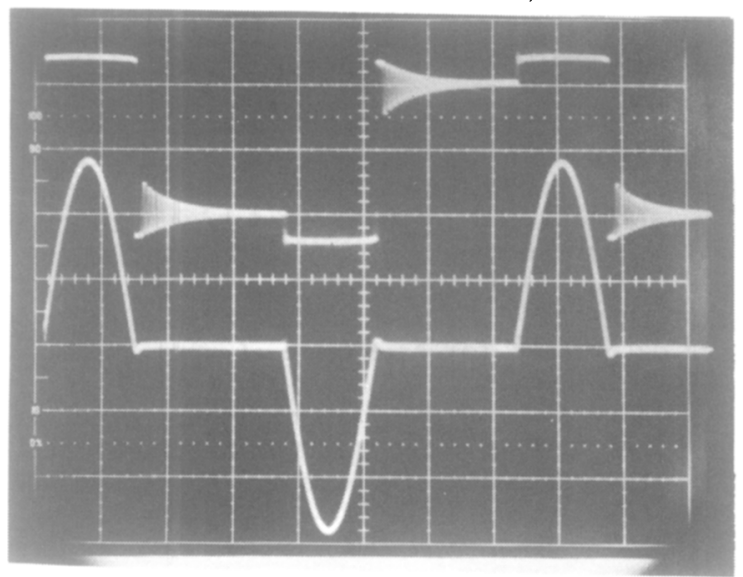

a)

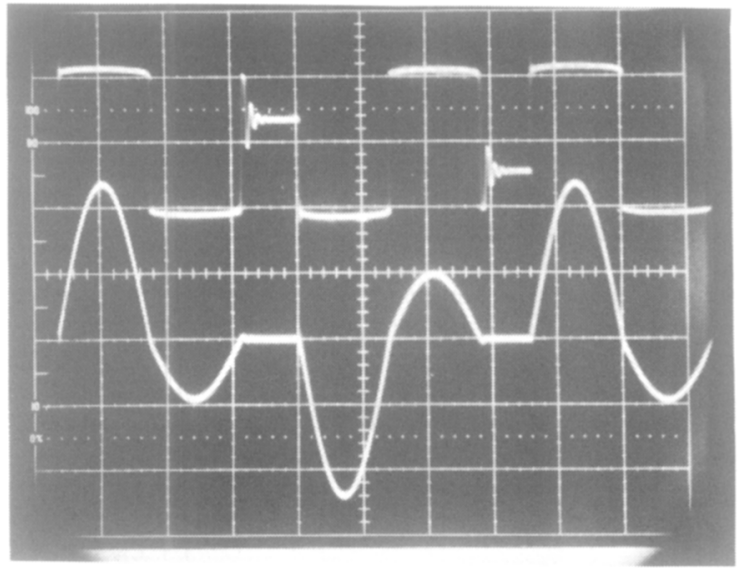

b)

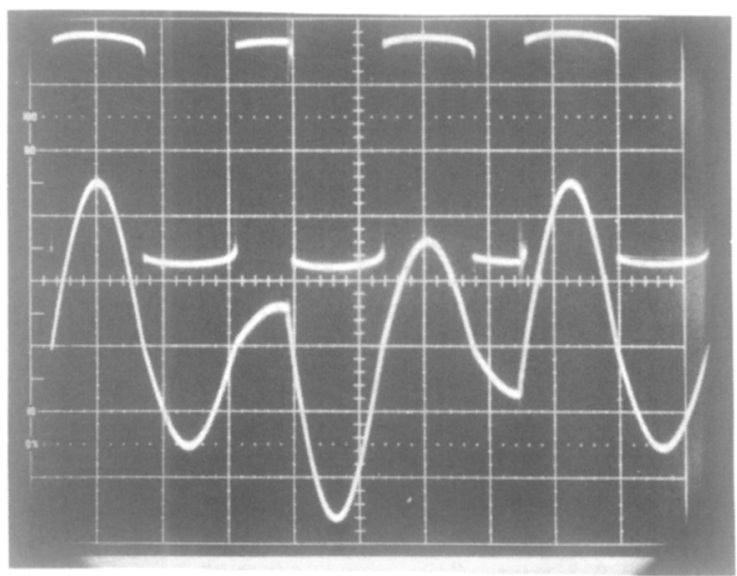

c)

Fig. 13. Experimental verification of how operation changes from (a) type $1 \mathrm{dcm}$ to (b) type $2 \mathrm{dcm}$ to $(\mathrm{c})$-type $2 \mathrm{ccm}$ as the load $R$ is reduced from $89 \Omega$ to $11 \Omega$.

Top trace is $\mathrm{V}_{B}$, bottom trace is $\mathrm{I}_{R}$ 


\section{CONCLUSION}

In this paper the dc operation of the series resonant converter has been analyzed in terms of two simple parameters: the load parameter $Q=\omega_{0} L / R$ and the ratio of switching frequency to resonant frequency. The discontinuous and continuous conduction modes have been identified in the general case and the conversion ratio $M$ has been determined for each mode of operation.

There are two general continuous conduction modes, defined as ttype $n \mathrm{ccm}$ and -type $n \mathrm{ccm}$, for which the conversion ratio $M$ is determined numerically.

There are two general discontinuous conduction modes defined as even type $n \mathrm{dcm}$ and odd type $n \mathrm{dcm}$. For the even type $n \mathrm{dcm}$ the conversion ratio $M$ is a linear function of the switching frequency and the load, whereas in the odd type $\mathrm{n}$ dcm the conversion ratio is insensitive to variation in load and switching frequency.

The boundaries between discontinuous and continuous conduction mode are given in terms of the load and switching frequency.

\section{REFERENCES}

1. R. D. Middlebrook and Slobodan Ćuk, "A General Unified Approach to Modelling Switching Converter Power Stages," IEEE Power Electronics Specialists Conference, 1976 Record, pp. 18-34 (IEEE Publication 76CHl084-3 AES); also International $\mathrm{J}$. of Electronics, vol. 42, no. 6, pp. 521-550, June 1977.

2. Slobodan Cuk and R. D. Middlebrook, "A General Unified Approach to Modelling Switching Dc-to-Dc Converters in Discontinuous Conduction Mode," IEEE Power Electronics Specialists Conference, 1977 Record, pp. 3657 (IEEE Publication 77CH1213-8 AES).

3. R. D. Middlebrook and Slobodan Cuk, Advances in Switched-Mode Power Conversion, Vol. I and II, TESLACO, 1981 .

4. F. C. Schwarz, "An Improved Method of Resonant Current Pulse Modulation for Power Converters," IEEE Power Electroncis Specialists Conference, 1975 Record, pp. 194-204 (IEEE Publication 75CH0965-4 AES).
5. R. King and T. A. Stuart, "A Normalized Model for the Half-Bridge Series Resonant Inverter," IEEE Transactions on Aerospace and Electronics Systems, vol. AES-17, no. 2, March 1981, pp. 190-198.

6. E. Kitt1, "Transient Waveform Analysis of Switching Converter," DRSEL-TL-PE Tech. Rep. ECOM-4493. U.S. Army Electronics Command, Fort Monmouth, N.J., April 1977. 